\title{
Overcoming Energetic Barriers in Acetogenic C1 Conversion
}

\author{
Alexander Katsyv and Volker Müller* \\ Department of Molecular Microbiology \& Bioenergetics, Institute of Molecular Biosciences, Johann Wolfgang Goethe \\ University, Frankfurt am Main, Germany
}

Currently one of the biggest challenges for society is to combat global warming. A solution to this global threat is the implementation of a $\mathrm{CO}_{2}$-based bioeconomy and a $\mathrm{H}_{2}$-based bioenergy economy. Anaerobic lithotrophic bacteria such as the acetogenic bacteria are key players in the global carbon and $\mathrm{H}_{2}$ cycle and thus prime candidates as driving forces in a $\mathrm{H}_{2}$ - and $\mathrm{CO}_{2}$-bioeconomy. Naturally, they convert two molecules of $\mathrm{CO}_{2}$ via the Wood-Ljungdahl pathway (WLP) to one molecule of acetyl-CoA which can be converted to different C2-products (acetate or ethanol) or elongated to C4 (butyrate) or C5-products (caproate). Since there is no net ATP generation from acetate formation, an electron-transport phosphorylation (ETP) module is hooked up to the WLP. ETP provides

OPEN ACCESS

Edited by:

Uldis Kalnenieks,

University of Latvia, Latvia

Reviewed by:

Byung-Kwan Cho,

Korea Advanced Institute of Science and Technology, South Korea

Weihong Jiang,

Institute of Plant Physiology and Ecology, SIBS (CAS), China

*Correspondence:

Volker Müller

vmueller@bio.uni-frankfurt.de

Specialty section:

This article was submitted to

Synthetic Biology,

a section of the journal

Frontiers in Bioengineering and

Biotechnology

Received: 25 October 2020

Accepted: 19 November 2020

Published: 23 December 2020

Citation:

Katsyv A and Müller V (2020)

Overcoming Energetic Barriers in

Acetogenic C1 Conversion.

Front. Bioeng. Biotechnol. 8:621166.

doi: 10.3389/fbioe.2020.621166 the cell with additional ATP, but the ATP gain is very low, only a fraction of an ATP per mol of acetate. Since acetogens live at the thermodynamic edge of life, metabolic engineering to obtain high-value products is currently limited by the low energy status of the cells that allows for the production of only a few compounds with rather low specificity. To set the stage for acetogens as production platforms for a wide range of bioproducts from $\mathrm{CO}_{2}$, the energetic barriers have to be overcome. This review summarizes the pathway, the energetics of the pathway and describes ways to overcome energetic barriers in acetogenic C1 conversion.

Keywords: carbon capture, biofuels, electron transport, biohydrogen, hydrogen storage

\section{INTRODUCTION}

In times of global warming there is an immediate need to reduce green house gas emissions. $\mathrm{CO}_{2}$ is by far the most important based on atmospheric concentrations and there are several chemical as well as biological approaches to reduce the atmospheric $\mathrm{CO}_{2}$ concentration (Claassen et al., 1999; Dey, 2007; Anwar et al., 2018). One is to reduce $\mathrm{CO}_{2}$ emissions at the first place followed by efficient capture and storage of $\mathrm{CO}_{2}$ (Benson and Orr, 2008; Leung et al., 2014). Lithotrophic microbes that make their biomass from $\mathrm{CO}_{2}$ are prime candidates to solve both problems (Götz et al., 2016; Liew et al., 2016; Dürre, 2017; Heijstra et al., 2017). Traditionally, biotechnological processes that compete with oil-based processes use sugars to produce high-value end products (Naik et al., 2010). These approaches do not only produce $\mathrm{CO}_{2}$ but also compete for sugar that is a feedstock for humans (Ajanovic, 2011). In contrast, lithotrophic organisms do not produce but use $\mathrm{CO}_{2}$ as feedstock (Bengelsdorf et al., 2018). Lithotrophs fix $\mathrm{CO}_{2}$ for biomass production with energy derived from solar energy (photolithoautotrophs) or from the oxidation of an inorganic electron donor such as $\mathrm{H}_{2}$ (chemolithoautotrophs). The latter occurs in the dark and the absence of oxygen, and thus operates at low costs (Rittmann and Herwig, 2012). Lithotrophic, $\mathrm{H}_{2}$-oxidizing, 
$\mathrm{CO}_{2}$ fixing microorganisms are the methanogenic archaea that only produce methane (Wolfe, 1971; Zehnder and Brock, 1979; Enzmann et al., 2018) or the acetogenic bacteria that produce different end products such as acetate and ethanol or butyrate and formate (Müller et al., 2004; Drake et al., 2008). They are also metabolically flexible and grow lithotrophically on $\mathrm{H}_{2}+\mathrm{CO}_{2}$ or on $\mathrm{CO}$, but also heterotrophically on sugars, alcohols, carbonic acids, primary and secondary alcohols (Andreesen et al., 1973; Bache and Pfennig, 1981; Eichler and Schink, 1984; Drake et al., 1997, 2008; Ragsdale and Pierce, 2008; Schuchmann and Müller, 2016). Heterotrophic growth in almost every case goes along with reduction of $\mathrm{CO}_{2}$ to acetate (Müller, 2003). Thus, acetogens can couple oxidation of various organic and inorganic electron donors to the reduction of $\mathrm{CO}_{2}$ to acetate or the other before mentioned products. Therefore, acetogens are the most flexible organisms to be used for a biological approach to capture and store $\mathrm{CO}_{2}$ in the dark and absence of $\mathrm{O}_{2}$ (Daniell et al., 2012; Liew et al., 2016; Köpke and Simpson, 2020). Since $\mathrm{CO}_{2}$ fixation can be driven by $\mathrm{H}_{2}$ oxidation, these bacteria also capture and store $\mathrm{H}_{2}$, a key process in the biohydrogen economy (Bailera et al., 2017; Müller, 2019; Schwarz and Müller, 2020).

\section{ACETOGENIC BACTERIA AND THE WOOD-LJUNGDAHL PATHWAY}

Acetogenic bacteria are a phylogenetically very diverse group of strictly anaerobic bacteria ubiquitous in nature. They are characterized by a reductive pathway in which two mol of $\mathrm{CO}_{2}$ are reduced to one mol of acetyl-CoA and then further to acetate, the Wood-Ljungdahl pathway (WLP) (Figure 1; Ljungdahl, 1986; Wood et al., 1986). Reducing power can be derived from the oxidation of organic but also inorganic carbon sources. Some acetogens naturally produce ethanol and butyrate in addition and, therefore, they have come into focus of an alternative, $\mathrm{CO}_{2}$ based bioeconomy (Schiel-Bengelsdorf and Dürre, 2012; Dürre, 2017). Ethanol is also produced from $\mathrm{CO}_{2}, \mathrm{H}_{2}$ and $\mathrm{CO}$ (syngas) on a large industrial scale (Daniell et al., 2012; Bengelsdorf et al., 2018). Apart from these gaseous substrates used, other C1 substrates such as formic acid or methanol are promising feedstocks for an alternative bioeconomy using acetogens as biocatalysts (Cotton et al., 2019; Müller, 2019). In addition to the mere use as production platforms, acetogens are also promising candidates in the $\mathrm{H}_{2}$-economy as potential catalysts for $\mathrm{H}_{2}$ storage or production (Bailera et al., 2017; Schwarz et al., 2018; Schwarz and Müller, 2020).

Among the naturally occurring carbon fixation pathways the WLP is the only pathway that does not need additional ATP to operate (Ragsdale and Pierce, 2008; Fuchs, 2011). One mol of $\mathrm{CO}_{2}$ is reduced to formate and then bound to the $\mathrm{C} 1$-carrier tetrahydrofolate (THF), driven by the hydrolysis of ATP (Himes and Harmony, 1973; Lovell et al., 1988). From the formyl-THF, water is split off and the produced methenyl-THF is further reduced via methylene- to methyl-THF (Clark and Ljungdahl, 1982). The latter condenses with CO and coenzyme A (CoA) on the enzyme acetyl-CoA synthase/CO dehydrogenase to acetyl$\mathrm{CoA}$; the $\mathrm{CO}$ derives from the reduction of another $\mathrm{CO}_{2}$ by the CO dehydrogenase (Drake et al., 1980; Pezacka and Wood, 1984; Ragsdale and Wood, 1985; Raybuck et al., 1988; Seravalli et al., 1997). Acetyl-CoA is then converted via acetyl phosphate to acetate and ATP. Thus the net synthesis of ATP by substrate level phosphorylation is zero. Since the bacteria grow by production of acetate from $\mathrm{H}_{2}+\mathrm{CO}_{2}$ there must be additional mechanisms to generate ATP (Schaupp and Ljungdahl, 1974; Drake et al., 1981; Müller, 2003).

\section{CHEMIOSMOTIC ENERGY CONSERVATION IN ACETOGENS}

Currently, acetogens can be divided into two bioenergetic groups, the Rnf- and the Ech-acetogens (Figure 2; Schuchmann and Müller, 2014). The Rnf- and the Ech-complex are membranebound respiratory enzymes that both use reduced ferredoxin as reductant (Schmehl et al., 1993; Hedderich and Forzi, 2005; Buckel and Thauer, 2018b). The Rnf complex has six subunits and catalyzes ferredoxin: $\mathrm{NAD}^{+}$oxidoreductase activity; the free energy change of the electron transport is coupled to the extrusion of ions from the cytoplasm to the periplasm thus generating an electrochemical ion gradient across the membrane that drives ATP synthesis via a $\mathrm{F}_{1} \mathrm{~F}_{\mathrm{O}}$ ATP synthase (Müller et al., 2008; Biegel and Müller, 2010; Westphal et al., 2018). The coupling ion maybe $\mathrm{Na}^{+}$as in the case of Acetobacterium woodii or $\mathrm{H}^{+}$as suggested for Clostiridum ljungdahlii or Clostridium autoethanogenum (Biegel and Müller, 2010; Tremblay et al., 2012; Kuhns et al., 2020). Two points are important to make: first, the nature of the coupling ion used has dramatic consequences for the energetic status, especially under stress conditions and second, NADH is the end product of this respiration and can be regarded as a waste product that needs to be recycled (reoxidized). Thus, by metabolic engineering, any reductive, NADH consuming pathway can be hooked up to the Rnf complex. In the second group, the Ech-acetogens, with Thermoanaerobacter kivui and Moorella thermoacetica as model strains, reduced ferredoxin is oxidized by an 8- or 9subunit, membrane-bound enzyme that transfers the electron to protons, thus producing molecular $\mathrm{H}_{2}$ (Pierce et al., 2008; Schoelmerich and Müller, 2020). This electron transport is coupled to the export of ions across the cytoplasmic membrane and the electrochemical ion gradient established drives the synthesis of ATP via a $\mathrm{F}_{1} \mathrm{~F}_{\mathrm{O}}$ ATP synthase (Welte et al., 2010; Schoelmerich and Müller, 2019). Three points are important to make here: first, the nature of the ferredoxin involved and its redox potential is not known. A. woodii, for example, has seven genes potentially encoding a ferredoxin. Since the $\mathrm{CO}_{2} / \mathrm{CO}$ couple $\left(\mathrm{E}_{0}^{\prime}\left[\mathrm{CO}_{2} / \mathrm{CO}\right]=-520 \mathrm{mV}\right)$ requires a low potential reductant we calculate with a redox potential of -450 to $-500 \mathrm{mV}$. Second, the potential difference between reduced ferredoxin $\left(\mathrm{E}_{0}{ }^{\prime}\left[\mathrm{Fd}^{2-} / \mathrm{Fd}\right] \sim-450\right.$ to $-500 \mathrm{mV}$ ) and protons $\left(\mathrm{E}_{0}{ }^{\prime}\left[\mathrm{H}_{2} / \mathrm{H}^{+}\right]=-414 \mathrm{mV}\right)$ is only about half $\left(\Delta \mathrm{E}_{0}{ }^{\prime}=+86 \mathrm{mV}\right.$ to $+36 \mathrm{mV}$ ) of the difference of the redox couple reduced ferredoxin:NAD ${ }^{+}\left(\Delta \mathrm{E}_{0}{ }^{\prime}=+180 \mathrm{mV}\right)$ and thus, only about half the amount of ions can be translocated per electron transported. 


\section{Methyl branch}

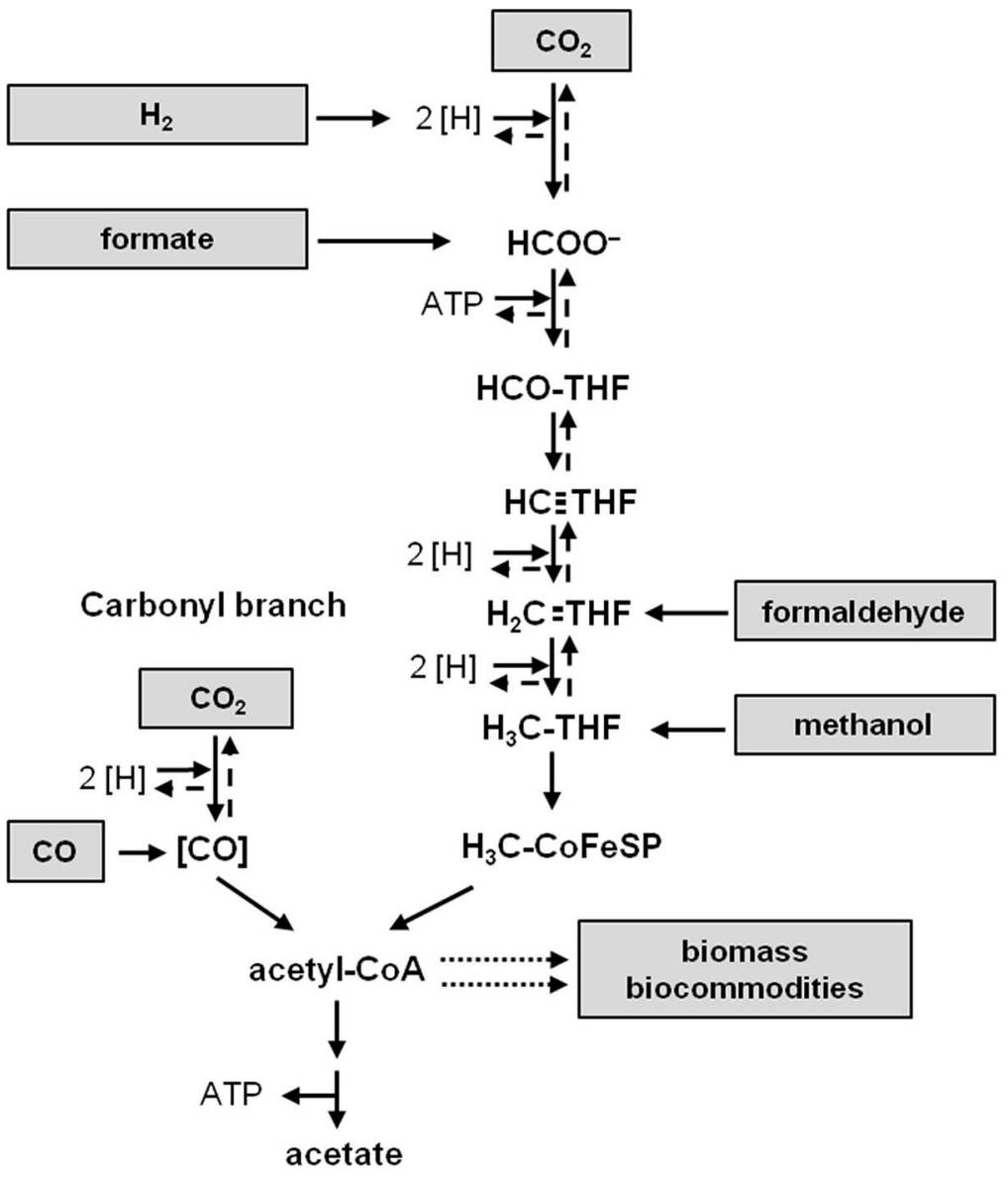

FIGURE 1 | The Wood-Ljungdahl pathway of $\mathrm{CO}_{2}$ reduction. Substrates fed directly into the pathway are shown to the left and right. Acetyl-CoA is the precursor of biomass and biocommodities (dotted arrows). [H], reducing equivalents; THF, tetrahydrofolic acid; [CO], enzyme-bound CO; large dashed arrows, oxidative direction of the pathway.

These numbers have not been determined for any Rnf- or Echcomplex but based on thermodynamics we consider two ions per two electrons in Rnf and one ion per two electrons in Ech as maximum. Third, the product of respiration is the volatile gas $\mathrm{H}_{2}$ and thus there is no need for a reductive pathway to be hooked up to the respiration since the electron escapes into the environment as gas. Although this is attractive for the cells it can be deleterious to the cell if the $\mathrm{H}_{2}$ partial pressure in the ecosystem is so high that it exhibits a thermodynamic backup pressure on the enzyme so that respiration comes to an end. The $\Delta \mathrm{G}^{0^{\prime}}$ of the reaction ferredoxin: $\mathrm{H}^{+}$is only -7 to -16.6 $\mathrm{kJ} / \mathrm{mol}$. This allows $\mathrm{H}_{2}$ production only up to a partial pressure of $0.05 \mathrm{MPa}$.

The function of Rnf as respiratory enzyme has been proven by genetic (Westphal et al., 2018) and biochemical experiments (Biegel and Müller, 2010) and recently, the final proof has been obtained using the enzyme from a thermophilic fermenting bacterium, Thermotoga maritima (not an acetogen) (Kuhns et al., 2020) as well as the acetogen $A$. woodii (Wiechmann and Müller, unpublished data). The enzyme was purified and reconstituted into liposomes and catalyzed electron transfer from reduced ferredoxin to $\mathrm{NAD}^{+}$; this electron transport was coupled to a primary and electrogenic $\mathrm{Na}^{+}$transport into the lumen of the liposomes (Wiechmann and Müller, unpublished data). For Ech, there is evidence that inverted membrane vesicles of the acetogen T. kivui couple $\mathrm{H}^{+}$as well as $\mathrm{Na}^{+}$transport into the lumen of the vesicles to $\mathrm{H}_{2}$ production from reduced ferredoxin (Schoelmerich and Müller, 2019). However, this organism has two Ech-encoding gene clusters and the final proof of ion translocation and the ion used has to await genetic studies and its purification and reconstitution into liposomes. Ion transport coupled to Ech-catalyzed reaction has also been observed in vesicles of the methanogenic archaeon Methanosarcina mazei (Welte et al., 2010) and there is no reason to believe that Ech 


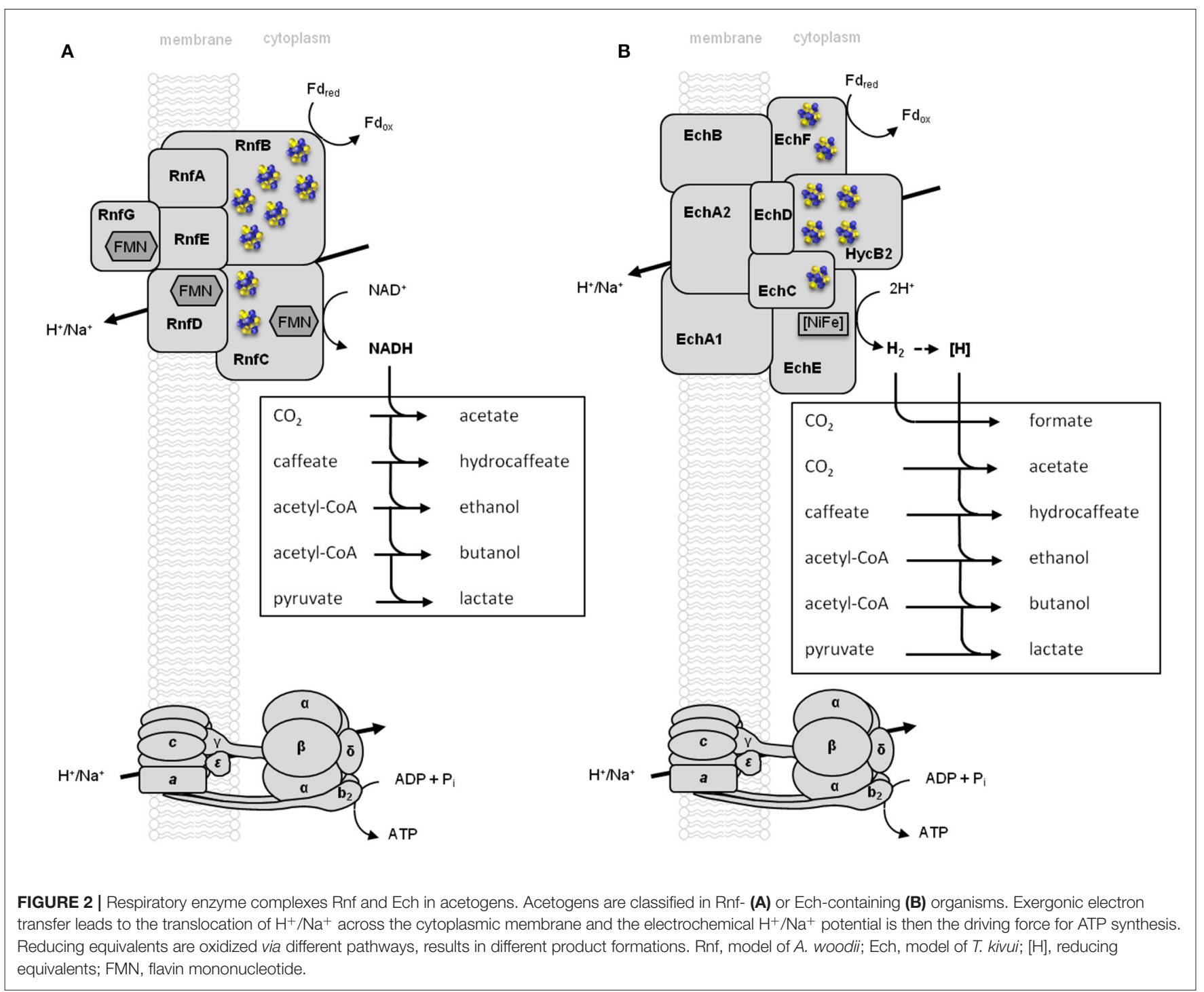

is not as respiratory enzyme in acetogens. This is different in cytochrome-containing acetogens. A. woodii and T. kivui do not contain cytochromes, but some acetogens like $M$. thermoacetica do. Historically, the discovery of cytochromes in the acetogens Clostridium formicoaceticum and M. thermoacetica was an exciting discovery since it immediately argued for a respiratory chain involved in acetogenesis (Gottwald et al., 1975). Unfortunately, 45 years after their discovery there is no evidence for that. Indeed, it may well be that cytochromes are not involved in acetogenesis $\left(\mathrm{CO}_{2}\right.$ reduction) but reduction of alternative electron acceptors such as nitrate (Visser et al., 2016). Since the involvement of cytochromes in acetogenesis is still a molecular hallucination, we will not discuss this further in this review.

The ion gradient established by the Rnf and Ech complex is then used by a $\mathrm{F}_{1} \mathrm{~F}_{\mathrm{O}}$-ATP-synthase to drive the synthesis of ATP. $\mathrm{F}_{1} \mathrm{~F}_{\mathrm{O}}$-ATP-synthases have been purified from only a few acetogens such as M. thermoacetica (Ivey and Ljungdahl, 1986), Moorella thermoauthotrophica (Das et al., 1997), A. woodii
(Reidlinger and Müller, 1994) and Eubacterium limosum (Litty and Müller, 2020). $\mathrm{F}_{1} \mathrm{~F}_{\mathrm{O}}$-ATP-synthases are macromolecular machines that convert electrochemical energy via mechanical energy into chemical energy (ATP) (Müller and Grüber, 2003). They are composed of two motors that are connected by a central stalk. Ion flow through the membrane-embedded motor made of the rotor (a ring of $c$ subunits) and the stator ( $a$ subunit) drives rotation of the rotor against the stator. Furthermore, rotation of the $c$-ring drives rotation of the central stalk that interacts with the three ATP synthesizing centers in the hydrophilic $\mathrm{F}_{1}$ domain, leads to the synthesis of ATP from ADP $+\mathrm{P}_{\mathrm{i}}$. The $c$ subunit harbors the ion binding site which are protons in most ATP synthases (Müller and Grüber, 2003; Meier et al., 2006; Grüber et al., 2014) and $\mathrm{Na}^{+}$in a few (Meier et al., 2009; Brandt and Müller, 2015; Mayer et al., 2015). Protons are bound to the so-called active carboxylate in helix two of the $c$ subunit (a aspartate or glutamate residue) (Fillingame et al., 2003) whereas the conserved $\mathrm{Na}^{+}$-binding site has in 
addition two residues, a glutamine in helix one and a serine or threonine residue downstream of the active carboxylate (Rahlfs and Müller, 1999; Müller and Grüber, 2003). There are more residues involved in complexing $\mathrm{Na}^{+}$(Meier et al., 2005) but these three are the conserved ones that make the conserved $\mathrm{Na}^{+}$binding motif. C. ljungdahlii and C. autoethanogenum only have the active carboxylate but not the $\mathrm{Na}^{+}$-binding motif (Mayer et al., 1986), whereas A. woodii (Reidlinger et al., 1994; Matthies et al., 2014) as well as E. limosum (Litty and Müller, 2020) have the conserved $\mathrm{Na}^{+}$-binding motif. The activity of the purified enzymes is strictly $\mathrm{Na}^{+}$dependent and the enzymes translocate $\mathrm{Na}^{+}$after reconstitution into liposomes (Fritz and Müller, 2007; Litty and Müller, 2020).

A critical number for bioenergetic calculations is the number of $c$ subunits per ring because this gives the number of ions translocated for the synthesis of three moles of ATP. This number has been experimentally determined only for A. woodii; in this case the $c$ ring has $10 \mathrm{Na}^{+}$-binding sites (Matthies et al., 2014). Divided by three ATP synthesizing centers that gives $3.3 \mathrm{Na}^{+} /$ATP. The non-acetogenic Clostridium paradoxum has $11 \mathrm{H}^{+}$-binding sites, giving a stoichiometry of $3.6 \mathrm{H}^{+}$/ATP (Ferguson et al., 2006; Meier et al., 2006). This number is used in this review to calculate the overall ATP yields in C. autoethanogenum.

\section{ELECTRON CARRIERS IN THE WLP}

After having discussed that acetogens have either one of the two respiratory enzymes Rnf or Ech the obvious question is: what are the cofactors of the other dehydrogenases/reductases in the WLP and how is the pool of reduced ferredoxin maintained. The first enzyme in the carbonyl branch is the acetyl-CoA synthase/CO dehydrogenase which is also the key enzyme in the entire pathway (Drake et al., 1980; Pezacka and Wood, 1984; Ragsdale and Wood, 1985; Raybuck et al., 1988; Seravalli et al., 1997). Due to the low redox potential of the $\mathrm{CO}_{2} / \mathrm{CO}$ couple $\left(\mathrm{E}_{0}^{\prime}\left[\mathrm{CO}_{2} / \mathrm{CO}\right]=-520 \mathrm{mV}\right)$ only reduced ferredoxin can act as reductant here. How ferredoxin $\left(\mathrm{E}_{0}^{\prime}\left[\mathrm{Fd}^{2-} / \mathrm{Fd}\right] \sim-450\right.$ to $-500 \mathrm{mV})$ is reduced with $\mathrm{H}_{2}\left(\mathrm{E}_{0}{ }^{\prime}\left[\mathrm{H}_{2} / \mathrm{H}^{+}\right]=-414 \mathrm{mV}\right)$ has been an enigma for a long time. With the discovery of electron bifurcation to couple endergonic with exergonic redox reactions (Li et al., 2008; Buckel and Thauer, 2018a), the solution was at hand: an electron-bifurcating hydrogenase (Schut and Adams, 2009). Such an enzyme is indeed also present in A. woodii. It couples the exergonic electron flow from $\mathrm{H}_{2}$ to $\mathrm{NAD}^{+}\left(\mathrm{E}_{0}{ }^{\prime}\right.$ $\left.\left[\mathrm{NAD}^{+} / \mathrm{NADH}\right]=-320 \mathrm{mV}\right)$ to the endergonic electron flow from $\mathrm{H}_{2}$ to ferredoxin (Schuchmann and Müller, 2012). In this context it is important to note that electron bifurcation is often mistakenly considered as mechanism for energy conservation. It is not, but it saves cellular energy. If electron transport from $\mathrm{H}_{2}$ to ferredoxin would be driven by ATP, at least one ATP would have to be invested. With electron bifurcation the equivalent of only a fraction of an ATP can be invested. This kind of energy saving is a prerequisite for life at the thermodynamic limit as in acetogens. Therefore, acetogens employ a multitude of different electron-bifurcating enzymes in their metabolism and, actually most of the various electron-bifurcating enzymes known to date are from acetogens (Müller et al., 2018).

The first step in the methyl branch is the reduction of $\mathrm{CO}_{2}$ to formate. Since the redox potential of the $\mathrm{CO}_{2} /$ formate couple is $-420 \mathrm{mV}$, neither $\mathrm{NAD}^{+}$nor $\mathrm{NADP}^{+}$can be used as reductant. The solution is different in different acetogens: some use a ferredoxin-dependent formate dehydrogenase, others a combination of an electron-bifurcating hydrogenase and an electron-bifurcating formate dehydrogenase and still others use a $\mathrm{H}_{2}$-dependent $\mathrm{CO}_{2}$ reductase (HDCR) (Yamamoto et al., 1983; Nagarajan et al., 2013; Schuchmann and Müller, 2013; Wang et al., 2013a,b). In the latter, $\mathrm{H}_{2}$ is oxidized by a hydrogenase subunit of the HDCR and the electrons are transferred, most likely by two small iron-sulfur containing electron transfer subunits, to the formate dehydrogenase (Schuchmann and Müller, 2013). This is energetically feasible given the redox potential $\mathrm{E}_{0}{ }^{\prime}$ of $-420 \mathrm{mV}$ of the redox couple $\mathrm{CO}_{2}$ /formate and $-414 \mathrm{mV}$ of the $\mathrm{H}_{2} / 2 \mathrm{H}^{+}$couple. In the electronbifurcating formate dehydrogenase of C. autoethanogenum, the same is achieved but by two consecutive reactions: first, a $\mathrm{NADP}^{+}$-specific electron-bifurcating hydrogenase reduces $\mathrm{NADP}^{+}$and ferredoxin and second, an electron-bifurcating formate dehydrogenase uses $\mathrm{NADP}^{+}$and reduced ferredoxin for $\mathrm{CO}_{2}$ reduction (Wang et al., 2013a). The next reduction step is the reduction of methenyl-THF to methylene-THF, catalyzed by the methylene-THF dehydrogenase. This enzyme maybe $\mathrm{NAD}^{+}$specific as in $A$. woodii or $\mathrm{NADP}^{+}$specific as in $C$. autoethanogenum or Sporomusa ovata (O'Brien et al., 1973; Ragsdale and Ljungdahl, 1984; Wang et al., 2013a; Kremp et al., 2020). The last reduction step is the reduction of methyleneTHF to methyl-THF, catalyzed by the methylene-THF reductase (MTHFR). This enzyme is of special interest in the bioenergetics of acetogens and it was proposed 43 years ago by Thauer et al. (1977) to be an energetic coupling site. This is based on the high redox potential of the pair methylene-/methyl-THF of $-200 \mathrm{mV}$, arguing that its reduction with $\mathrm{NADH}$ would deliver sufficient energy to be used in energy conservation (Wohlfarth and Diekert, 1991). Accordingly, it was speculated for a long time that the methylene-THF reductase is the terminal acceptor of a respiratory chain that energizes the cytoplasmic membrane for ATP synthesis (Müller, 2003). However, with the genomic sequences for acetogens and the biochemical data available this can be ruled out for the model strains analyzed. Nevertheless, the enzyme could use electron bifurcation (Buckel and Thauer, 2018a; Müller et al., 2018) to couple the exergonic reduction of methylene- to methyl-THF with the endergonic reduction of ferredoxin which then drives energy conservation in the respiratory chain. Indeed, the enzymes from $M$. thermoacetica or C. ljungdahlii do not couple NADH oxidation to methylene-THF reduction, indicating that a second electron acceptor is missing (Moore et al., 1974; Clark and Ljungdahl, 1984; Mock et al., 2014). Since it is a characteristic of electron-bifurcating enzymes that they are only active in presence of all three reaction partners, the lack of activity was taken to suggest that the enzyme is electron bifurcating to an unknown second acceptor (Mock et al., 2014). However, this still needs to be verified. In contrast, $A$. woodii has a $\mathrm{NAD}^{+}$-dependent, non-electron-bifurcating methylene-THF 
reductase (Bertsch et al., 2015). In sum, the electron carriers used by the enzymes of the WLP are very different.

\section{ELECTRON CARRIERS INVOLVED IN SUBSTRATE OXIDATION}

The diversity also holds true for the electron carriers involved in substrate oxidation. Sugars such as glucose, fructose, mannitol are oxidized by the Embden-Meyerhof-Parnas pathway with $\mathrm{NAD}^{+}$in the glycerol-3-phosphate dehydrogenase reaction and ferredoxin in the pyruvate:ferredoxin oxidoreductase reaction as electron carriers. Other substrates such as ethanol only yield $\mathrm{NADH}$ and still others such as formate only yield molecular $\mathrm{H}_{2}$ (Schuchmann and Müller, 2013; Bertsch et al., 2016). During lithotrophic growth, $\mathrm{H}_{2}$ is oxidized by an electron-bifurcating hydrogenase yielding both, NADH and reduced ferredoxin (Schuchmann and Müller, 2012). In Ech-containing acetogens, $\mathrm{H}_{2}$ oxidation could theoretically yield reduced ferredoxin by $\mathrm{Ni}$ Fe hydrogenases (Ech-complex), as shown in the methanogenic archaeon Methanosarcina barkeri (Meuer et al., 2002). CO is oxidized by the $\mathrm{CO}$ dehydrogenase coupled to reduction of ferredoxin (Seravalli et al., 1997). In sum, oxidation of different substrates yields different reduced electron carriers such as $\mathrm{NADH}, \mathrm{NADPH}$, reduced ferredoxin, $\mathrm{H}_{2}$ or combinations thereof, whereas the WLP only accepts, species specific, distinct electron donors in the right stoichiometry. Thus, there is an essential need to switch and adjust the electron carriers between the oxidation module and the WLP.

\section{ELECTRON CARRIER ADJUSTMENT: MANY VARIATIONS OF A THEME}

Conversion of redox carriers into each other requires energy and since acetogens life at the thermodynamic edge of life, they have evolved energy-efficient ways. They employ specialized membrane-bound and soluble enzyme systems. The membranebound enzymes are the before discussed respiratory enzymes Rnf and Ech. They are both coupled reversibly to the membrane potential. In the above described function they serve to reduce $\mathrm{NAD}^{+}\left(\mathrm{E}_{0}^{\prime}\left[\mathrm{NAD}^{+} / \mathrm{NADH}\right]=-320 \mathrm{mV}\right)$ with reduced ferredoxin $\mathrm{E}_{0}^{\prime}\left[\mathrm{Fd}^{2-} / \mathrm{Fd}\right] \sim-450$ to $-500 \mathrm{mV}$ ) as reductant or to reduce protons to $\mathrm{H}_{2}\left(\mathrm{E}_{0}^{\prime}\left[\mathrm{H}_{2} / 2 \mathrm{H}^{+}\right]=-414 \mathrm{mV}\right)$. During growth on low energy substrates that only yield $\mathrm{NADH}, A$. woodii employs the Rnf to drive reverse electron transport (Hess et al., 2013b; Westphal et al., 2018). This is actually the function in most organisms and this function was decisive for the name giving: Rhodobacter nitrogen fixation (Schmehl et al., 1993). There, the Rnf complex drives the endergonic reduction of ferredoxin, required for nitrogen fixation, with NADH as reductant (Schmehl et al., 1993; Kumagai et al., 1997; Saeki and Kumagai, 1998). Analogously, the Ech complex can drive the endergonic reduction of ferredoxin with $\mathrm{H}_{2}$ as reductant at the expense of the electrochemical ion gradient across the membrane (Meuer et al., 2002). The same function is achieved by the soluble electron-bifurcating hydrogenase that couples $\mathrm{H}_{2}$ oxidation to the reduction of both, $\mathrm{NAD}^{+}$(exergonic) and ferredoxin (endergonic) where the energy is provided by electron bifurcation (Schuchmann and Müller, 2012). Conversion of $\mathrm{NADP}^{+}$and $\mathrm{NAD}^{+}$is catalyzed with reduced ferredoxin as driver in the Nfn and Stn-type electron-bifurcating transhydrogenases found in acetogens and the electron-bifurcating hydrogenase/formate dehydrogenase complex connects cellular $\mathrm{H}_{2}, \mathrm{NADP}^{+}$, ferredoxin and $\mathrm{CO}_{2}$ pools (Wang et al., 2010; Nguyen et al., 2017; Kremp et al., 2020).

Together with the difference in electron carrier specificity of the substrate oxidation reaction and the WLP and the different respiratory enzymes this gives hundreds of possible combinations for energy conservation (Figure 3). Since acetogens growing on $\mathrm{H}_{2}+\mathrm{CO}_{2}$ make only a fraction of an ATP per mol of acetate formed, a change in the electron carrier specificity of a given metabolic scheme makes a huge difference for the ATP yield. Therefore, reliable calculation for the overall ATP gain can only be done with clear conscience for those organisms in which the electron carrier specificity of the redox reaction and the type of respiratory enzyme has been determined experimentally. Metabolic schemes with too many unknown variables are rather harmful than useful. Therefore, we will concentrate on the wellstudied acetogen $A$. woodii that grows very robust on $\mathrm{H}_{2}+\mathrm{CO}_{2}$ and is a prime candidate also for a biohydrogen economy, but that does not grow on CO or syngas, and on C. autoethanogenum (or its close relative, C. ljungdahlii), a working horse in the industrial production of biofuels from syngas but a less wellunderstood metabolism.

\section{BIOENERGETICS OF A. woodii AND C. autoethanogenum}

Acetogenesis from $\mathrm{H}_{2}+\mathrm{CO}_{2}$ or $\mathrm{CO}$ according to equations 1 and 2 goes along with a free energy change of -95 and $-175 \mathrm{~kJ} / \mathrm{mol}$.

$$
\begin{aligned}
4 \mathrm{H}_{2}+2 \mathrm{CO}_{2} & \rightarrow 1 \mathrm{CH}_{3} \mathrm{COO}^{-}+1 \mathrm{H}^{+}+2 \mathrm{H}_{2} \mathrm{O} \\
\Delta \mathrm{G}^{0^{\prime}} & =-95 \mathrm{~kJ} / \mathrm{mol} \\
4 \mathrm{CO}+2 \mathrm{H}_{2} \mathrm{O} & \rightarrow 1 \mathrm{CH}_{3} \mathrm{COO}^{-}+1 \mathrm{H}^{+}+2 \mathrm{CO}_{2} \\
\Delta \mathrm{G}^{0^{\prime}} & =-175 \mathrm{~kJ} / \mathrm{mol}
\end{aligned}
$$

Considering the $\mathrm{H}_{2}$ and $\mathrm{CO}$ concentration in the environment this is sufficient for only 0.3 and $1.5 \mathrm{~mol} \mathrm{ATP} / \mathrm{mol}$ acetate, respectively (Kim and Hegeman, 1983; Novelli et al., 1999; Schuchmann and Müller, 2014). The enzymology and bioenergetics of $A$. woodii and $C$. autoethanogenum for acetogenesis from $\mathrm{H}_{2}+\mathrm{CO}_{2}$ or $\mathrm{CO}$ is summarized in Figures 4 and 5. In $A$. woodii, not only the electron carriers are known but also the ion/ATP stoichiometry of the ATP synthase is known (3.3 Na+/ATP), the only case for acetogens (Matthies et al., 2014). This allows to calculate the ATP/acetate stoichiometry very accurately with $0.3 \mathrm{~mol} \mathrm{ATP} / \mathrm{mol}$ of acetate with $\mathrm{H}_{2}+\mathrm{CO}_{2}$ as substrate (Figure 4A). A. woodii does not grow on CO (Bertsch and Müller, 2015) but resting cells are able 


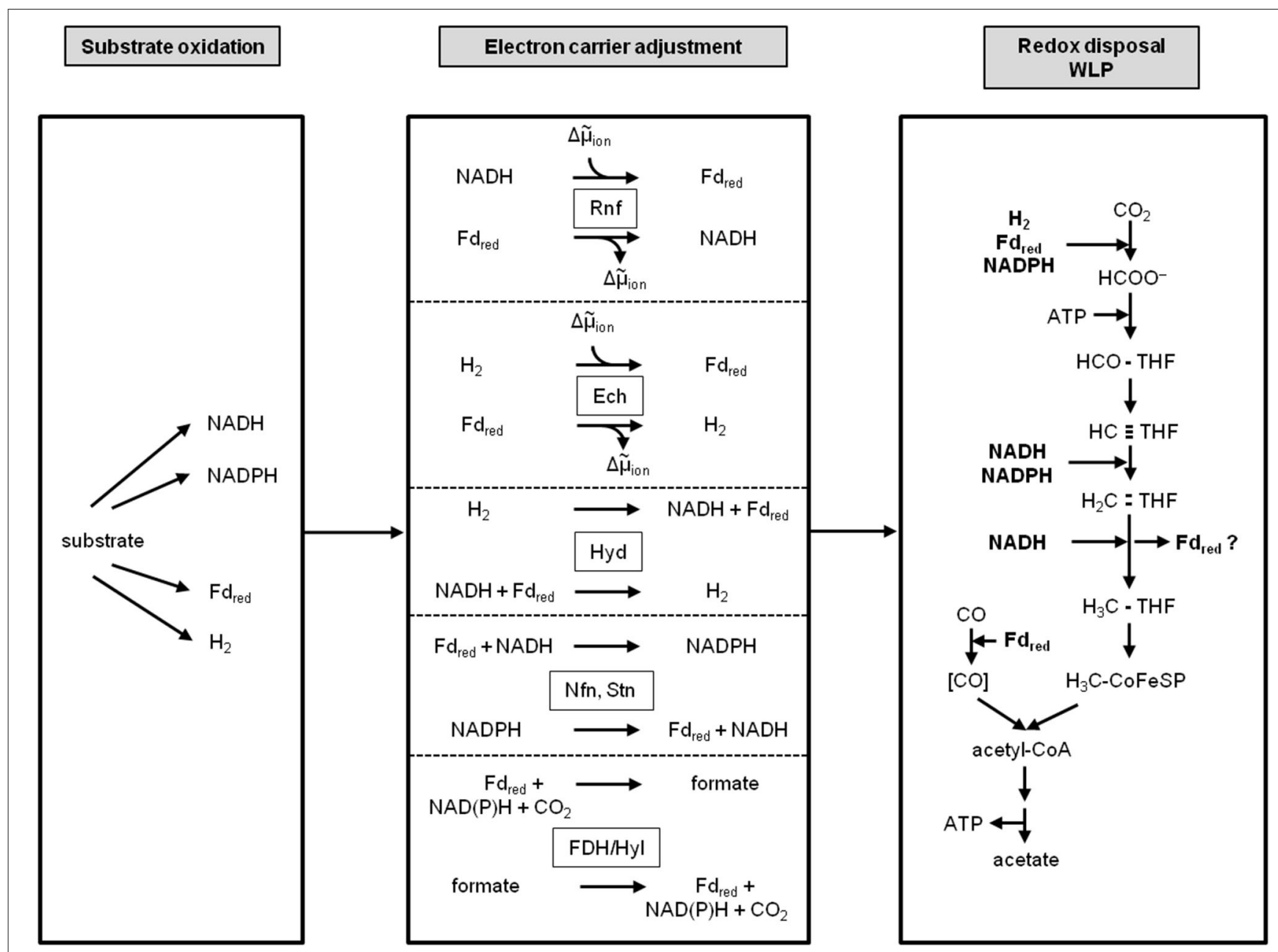

FIGURE 3 | Modularity of acetogenesis. Depending on the redox potential of the substrate, redox carriers with different redox potentials are reduced. The WLP requires species-specific, fixed sets of distinct electron carriers with different redox potentials. To switch electron carriers between the substrate oxidation module and the WLP, a third module that adjusts the electron carriers is required; it contains enzymes like Rnf, Ech, electron-bifurcating hydrogenase, Nfn/Stn or the electron-bifurcating hydrogenase/formate dehydrogenase complex. THF, tetrahydrofolic acid; Hyd, electron-bifurcating hydrogenase; FDH/Hyl, electron-bifurcating formate dehydrogenase; Nfn, electron-bifurcating, ferredoxin-dependent transhydrogenase; Stn, Sporomusa type Nfn.

to oxidize CO according to equation 2 (Diekert et al., 1986). This yields $1.5 \mathrm{ATP} / \mathrm{mol}$ of acetate (Figure $4 \mathrm{~B}$ ).

For C. autoethanogenum, there are two unknowns: the ion/ATP stoichiometry and whether or not the methylene-THF reductase (MTHFR) is electron bifurcating. For the calculations we have assumed an ion/ATP stoichiometry of 3.6 (see above) and for the methylene-THF reductase we assume either electron bifurcation with ferredoxin as second electron acceptor or no electron bifurcation. With these two variables, the ATP gain in C. autoethanogenum varies from 0.4 to $1 \mathrm{~mol} / \mathrm{mol}$ of acetate with $\mathrm{H}_{2}+\mathrm{CO}_{2}$ as substrate (Figures 5A,C). It should be mentioned that the ATP yield of acetogenesis from $\mathrm{H}_{2}+\mathrm{CO}_{2}$ in C. autoethanogenum is higher compared to $A$. woodii if an electron-bifurcating methylene-THF reductase is assumed (Figures 5A,B). With $\mathrm{CO}$ as electron donor, the energetic of acetogenesis is much better. According to equation 2, the $\Delta \mathrm{G}^{0^{\prime}}$ is $-175 \mathrm{~kJ} / \mathrm{mol}$ and acetate formation from $\mathrm{CO}$ in
C. autoethanogenum goes along with the synthesis of $1-1.5 \mathrm{~mol}$ ATP/mol acetate (Figures 5B,D). This is more than from $\mathrm{H}_{2}+$ $\mathrm{CO}_{2}$ but both values are still very low compared to fermenting bacteria or even aerobes (Müller, 2008). However, the situation gets worse when products other than acetate are formed from acetyl-CoA (Figure 6).

\section{BIOENERGETICS OF THE FORMATION OF PRODUCTS OTHER THAN ACETATE IN A. woodii AND C. autoethanogenum}

Acetyl-CoA acts as a precursor, not only for the production of acetate, but also for the formation of products like ethanol (Köpke et al., 2011a; Basen et al., 2014; Müller, 2014; Lo et al., 2015), butanol (Dürre et al., 1992), lactate (Gladden, 2004), 2,3 butanediol (Syu, 2001; Köpke et al., 2011b; Hess et al., 

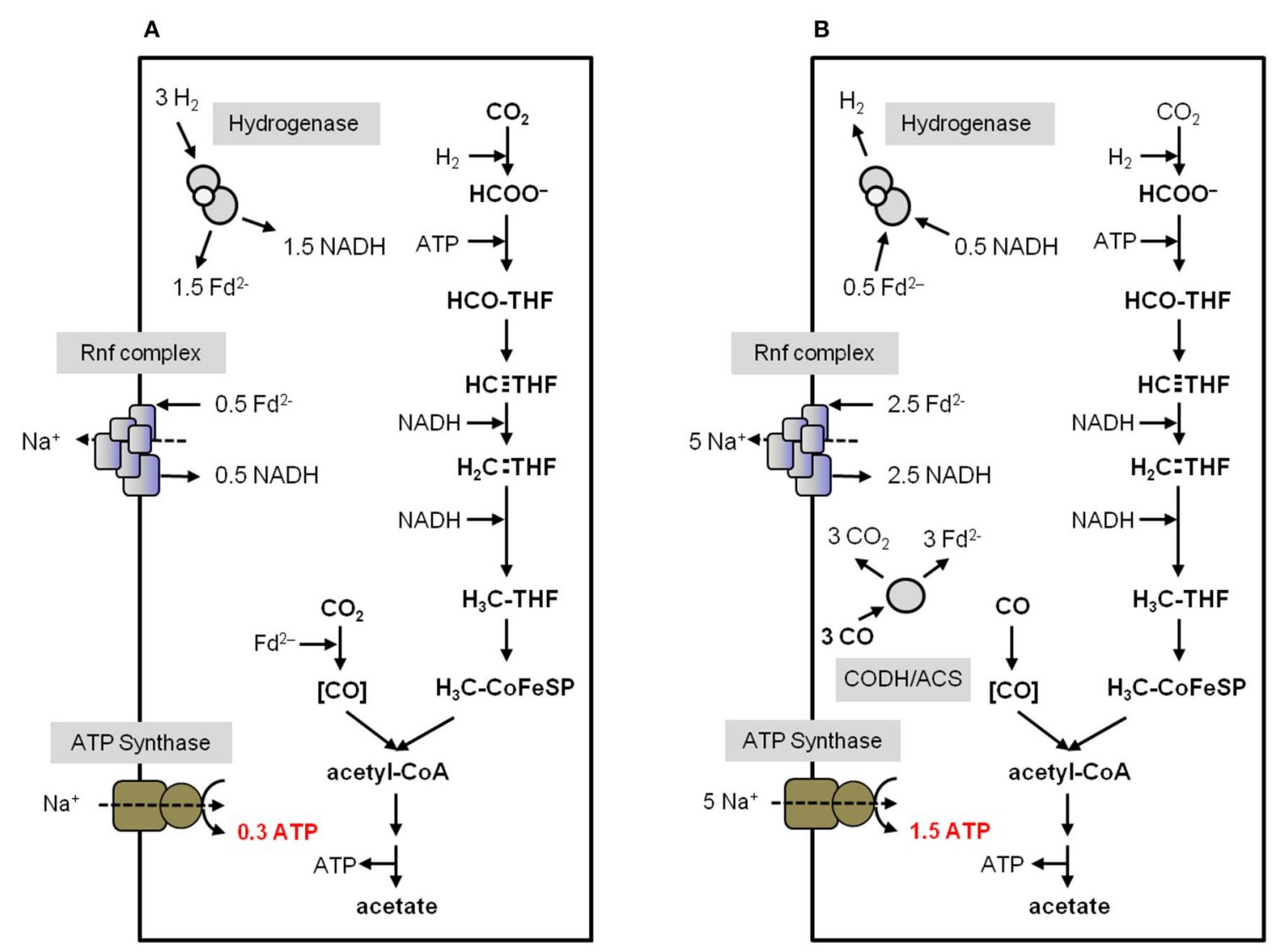

FIGURE 4 | Bioenergetics of acetate formation from $\mathrm{H}_{2}+\mathrm{CO}_{2}$ and $\mathrm{CO}$ in $\mathrm{A}$. woodii. The reducing equivalents for the reductive steps in the WLP (A) are provided by an $\mathrm{H}_{2}$-oxidizing, electron-bifurcating hydrogenase which reduces ferredoxin and $\mathrm{NAD}^{+}$. The reducing equivalents for the reductive steps during $\mathrm{CO}$ oxidation (B) are provided by the $\mathrm{CO}$-oxidizing $\mathrm{CODH} / \mathrm{ACS}$ which reduces ferredoxin. Excess $\mathrm{Fd}^{2-}$ is oxidized by the Rnf complex which reduces $\mathrm{NAD}^{+}$and builds up a Na+ gradient. This gradient drives ATP synthesis via the $\mathrm{Na}^{+}$-dependent ATP synthase. In total, 0.3 ATP from $\mathrm{H}_{2}+\mathrm{CO}_{2}$ and 1.5 ATP from CO can be synthesized per acetate produced. CODH/ACS, CO dehydrogenase/acetyl coenzyme A synthase; THF, tetrahydrofolic acid.

2015), acetone (Dürre et al., 1992; Hoffmeister et al., 2016), isobutene (van Leeuwen et al., 2012) or isoprene (Diner et al., 2018; Figure 6). As deduced above, the reduction of $\mathrm{CO}_{2}$ to acetyl-CoA with $\mathrm{H}_{2}$ in A. woodii requires 0.7 ATP (Figure 4A), whereas with $\mathrm{CO}$ as donor, $0.5 \mathrm{ATP}$ is produced (Figure 4B). C. authoethanogenum has an energy demand of 0.6 ATP when reducing $\mathrm{CO}_{2}$ to acetyl-CoA with $\mathrm{H}_{2}$ (Figure 5C), whereas with $\mathrm{CO}$ as donor, the ATP balance is zero (Figure 5D). Therefore, if the further conversion of acetyl-CoA to the desired product gains ATP, the production from $\mathrm{CO}$ will be possible. Whereas, from $\mathrm{H}_{2}+\mathrm{CO}_{2}$ it depends on the amount of ATP produced. In contrast, if the pathway to the desired product from acetyl$\mathrm{CoA}$ requires an input of ATP, the production from $\mathrm{H}_{2}+\mathrm{CO}_{2}$ will not be possible. With $\mathrm{CO}$ as electron and carbon source it depends on the amount of energy required. As mentioned above, the overall ATP yield can be higher in C. authoethanogenum, when an electron-bifurcating methylene-THF reductase is assumed. In this case the ATP balance is zero, when $\mathrm{CO}_{2}$ is reduced to acetyl-CoA with $\mathrm{H}_{2}$ (Figure 5A), whereas in contrast 0.5 ATP per acetyl-CoA is produced with $\mathrm{CO}$ as substrate (Figure 5B).
Ethanol can be made from acetyl-CoA by two reduction steps via acetaldehyde (Figure 6). The reduction of acetyl$\mathrm{CoA}$ to ethanol with $\mathrm{NADH}$ as electron donor is close to equilibrium $\left(\Delta \mathrm{G}^{0^{\prime}}=-6.2 \mathrm{~kJ} / \mathrm{mol}\right)$ and catalyzed by NADHdependent enzymes like the bifunctional AdhE (Thauer et al., 1977; Goodlove et al., 1989; Peng et al., 2008; Yakushi and Matsushita, 2010; Extance et al., 2013; Bertsch et al., 2016). Thus, $2 \mathrm{NADH}$ are required for the reduction of acetyl-CoA to ethanol. When a product like ethanol is formed from $\mathrm{H}_{2}$ $+\mathrm{CO}_{2}$ via acetyl-CoA, the ATP gained in the acetate kinase reaction is missing and the overall ATP gain is negative with a demand of $0.7 \mathrm{ATP} /$ per mol of ethanol in $A$. woodii. In addition, two more reducing equivalents are required; the reduction of 2 $\mathrm{NAD}^{+}$with $\mathrm{H}_{2}$ as electron donor yields 0.6 ATP by action of hydrogenase, Rnf complex, and ATP synthase. In sum, ethanol formation has an energy demand of 0.1 ATP (Table 1). With CO as electron donor, ethanol formation would be possible with an ATP yield of 1.7 ATP/ethanol (Table 1). The same holds true for C. authoethanogenum. It was shown, that C. autoethanogenum can produce ethanol when growing on CO (Abrini et al., 1994; Abubackar et al., 2015) or $\mathrm{H}_{2}+\mathrm{CO}_{2}$ as electron donor (Mock 
A

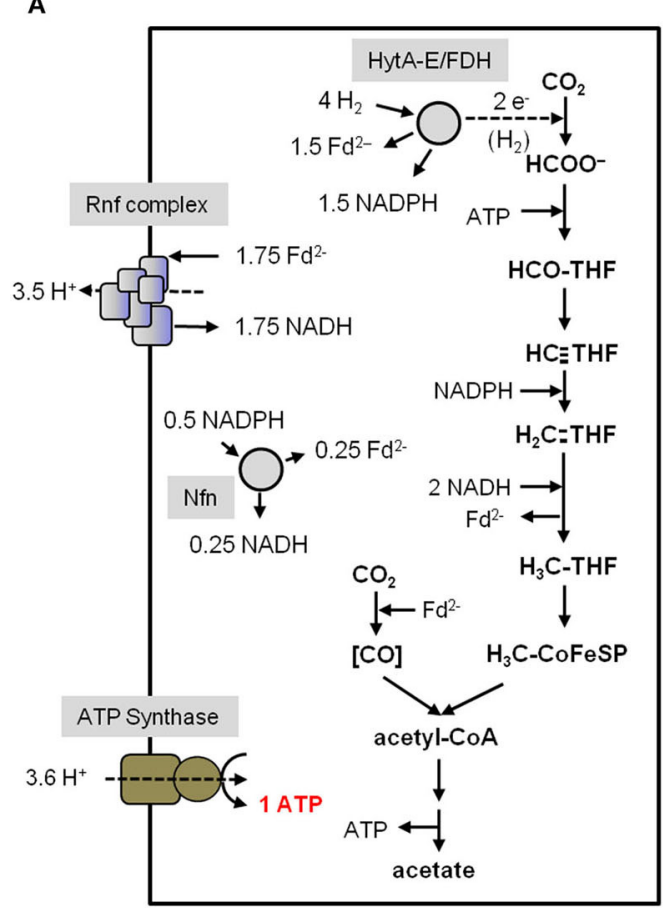

C

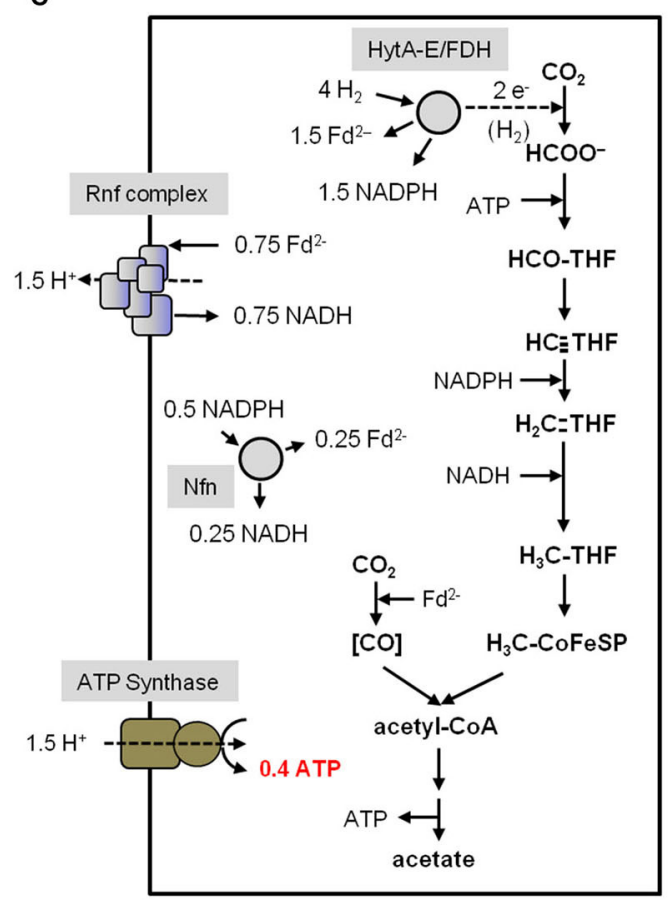

B

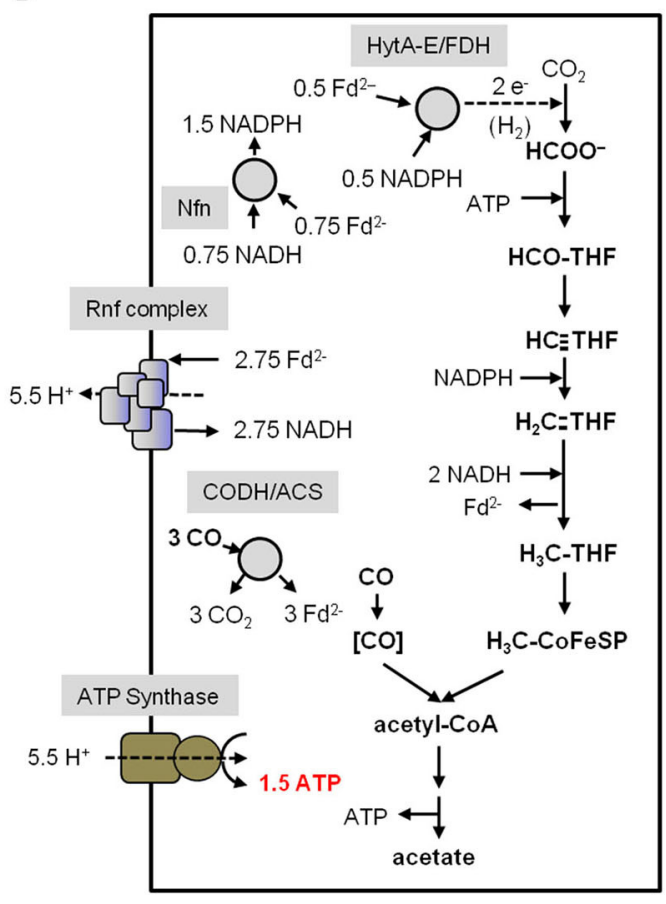

D

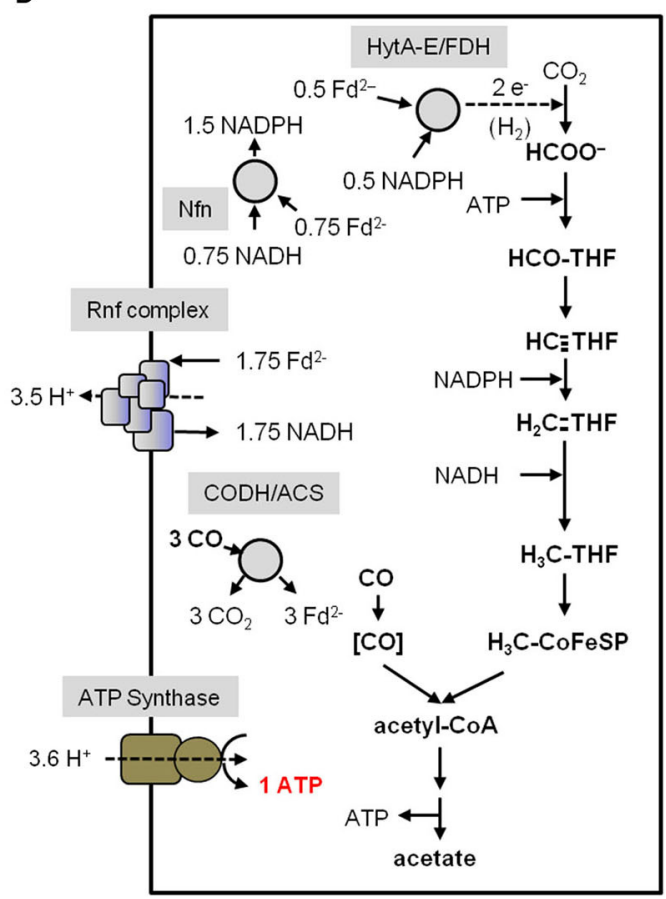

FIGURE 5 | Bioenergetics of acetate formation from $\mathrm{H}_{2}+\mathrm{CO}_{2}$ and $\mathrm{CO}$ in $\mathrm{C}$. autoethanogenum. The reducing equivalents for the reductive steps in the WLP (A,C) are provided by an $\mathrm{H}_{2}$-oxidizing, electron-bifurcating hydrogenase/formate dehydrogenase complex (HytA-E/FDH) which reduces Fd, $\mathrm{NADP}^{+}$and $\mathrm{CO}_{2}$. The reducing equivalents for the reductive steps during $\mathrm{CO}$ oxidation (B,D) are provided by the CO-oxidizing CODH/ACS which reduces Fd. The Nfn complex is transferring electrons between Fd, NADH and NADPH. The methylene-THF reductase is assumed to be electron bifurcating in $(\mathbf{A}, \mathbf{B})$. In $(\mathbf{C}, \mathbf{D})$ the methylene-THF reductase is not electron bifurcating. Excess $\mathrm{Fd}^{2-}$ is oxidized by the Rnf complex which reduces $\mathrm{NAD}^{+}$and builds up a $\mathrm{H}^{+}$gradient. This gradient drives ATP synthesis via the $\mathrm{H}^{+}$-dependent ATP synthase. In total, 0.4/1 ATP from $\mathrm{H}_{2}+\mathrm{CO}_{2}$ and 1/1.5 ATP from CO (depending on the MTHFR reaction) can be synthesized per acetate produced. CODH/ACS, CO dehydrogenase/acetyl coenzyme A synthase; THF, tetrahydrofolic acid; Nfn, electron-bifurcating and ferredoxin-dependent transhydrogenase. 


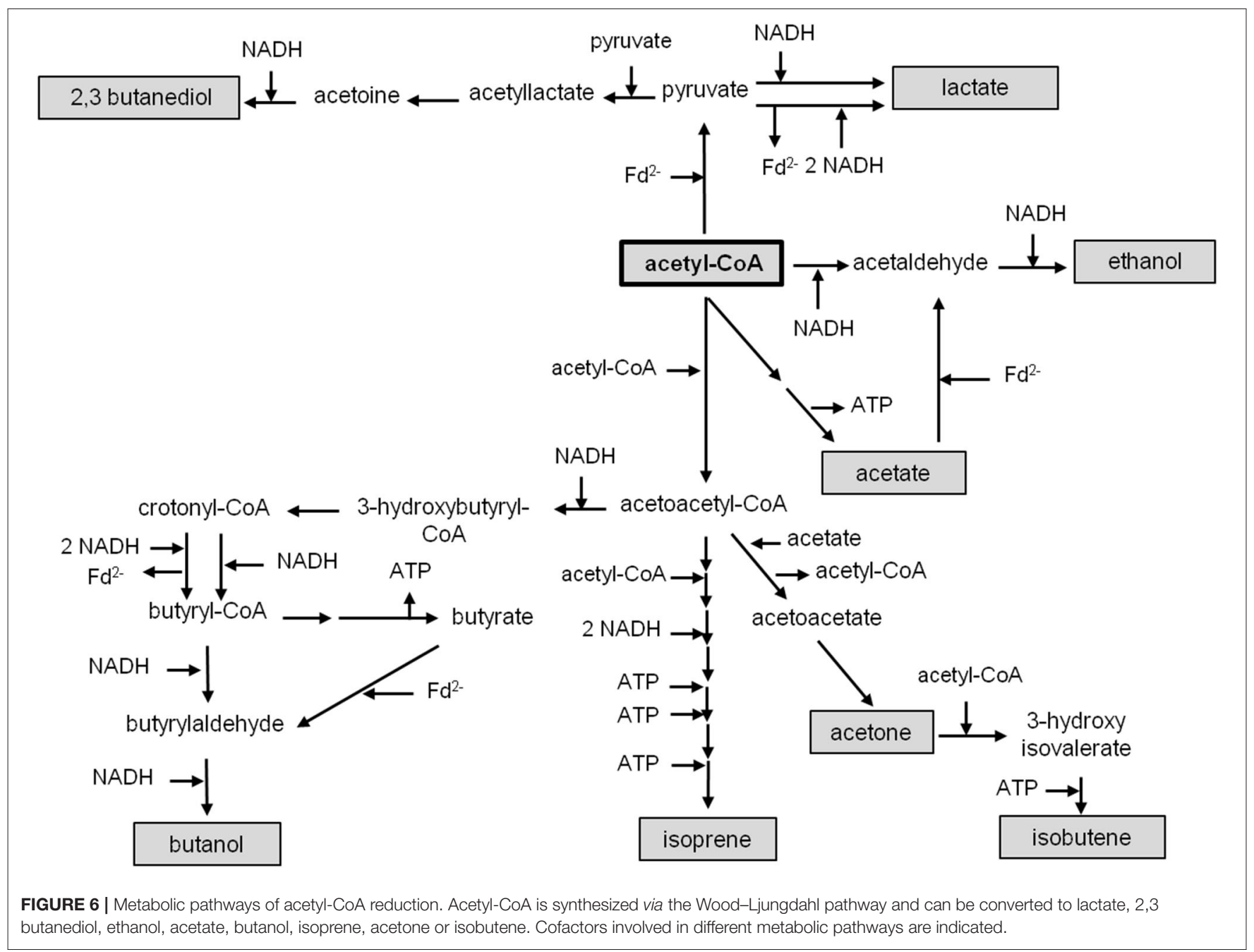

et al., 2015). Ethanol formation from $\mathrm{H}_{2}+\mathrm{CO}_{2}$ has an energy demand of 0.2 ATP and with CO an ATP gain of $1.4 \mathrm{ATP} /$ ethanol (Table 2). However, in C. autoethanogenum ethanol production from $\mathrm{H}_{2}+\mathrm{CO}_{2}$ could be possible, in comparison to A. woodii, if a bifurcating methylene-THF reductase is assumed. In this scenario, C. autoethanogenum would gain 0.4 ATP per produced ethanol (Table 2). With CO the energetics for ethanol production is even better with 1.9 ATP/ethanol (Table 2).

However, there is a second way of producing ethanol from acetyl-CoA in acetogens. Aldehyde:ferredoxin oxidoreductases (AOR) are capable of catalyzing the reversible reduction of an acid to the corresponding aldehyde, in this case, the reduction of acetate to acetaldehyde (White et al., 1989; Nissen and Basen, 2019). The importance of AOR enzymes are discussed in more detail later in this review. The redox potential of acetate/acetaldehyde $\left(\mathrm{E}_{0}{ }^{\prime}=-580 \mathrm{mV}\right)$ is so negative that a low potential electron donor such as ferredoxin is required (Thauer et al., 1977). The further reduction of acetaldehyde to ethanol could be catalyzed by a monofunctional alcohol dehydrogenase (ADH) (Goodlove et al., 1989), or by the same
AdhE as described above. Indeed, C. autoethanogenum has an AOR enzyme that together with $\mathrm{ADH}$ converts acetate to ethanol (Mock et al., 2015). Under these conditions, ethanol production from $\mathrm{H}_{2}+\mathrm{CO}_{2}$ yields 0.4/1.2 ATP/ethanol, while ethanol production from CO gains 1.9/2.4 ATP/ethanol (depending on the MTHFR reaction) (Table 2). A. woodii does not have an AOR (Poehlein et al., 2012), but if one is implemented by metabolic engineering, ethanol formation from $\mathrm{H}_{2}+\mathrm{CO}_{2}$ would be possible with an ATP yield of $0.3 \mathrm{ATP} /$ ethanol (Table 1). With $\mathrm{CO}$ as electron donor, the energetics for ethanol production with an implemented AOR in A. woodii are even better, yielding 2.1 ATP/ethanol (Table 1).

The production of other valuable products in A. woodii or C. autoethanogenum such as lactate, butanol, acetone, isobutene or 2,3-butanediol has an energy demand with $\mathrm{H}_{2}+\mathrm{CO}_{2}$ but a higher net ATP gain with CO as electron donor (Tables 1, 2). To form lactate, acetyl-CoA has to be first carboxylated to pyruvate by a pyruvate:ferredoxin oxidoreductase (Figure 6; Furdui and Ragsdale, 2000). Using NADH as electron donor, pyruvate is further reduced to lactate $\left(\Delta \mathrm{G}^{0^{\prime}}=-25 \mathrm{~kJ} / \mathrm{mol}\right)$ 
TABLE 1 | ATP yield for the synthesis of products from acetyl-CoA with $\mathrm{H}_{2}+\mathrm{CO}_{2}$ or $\mathrm{CO}$ as electron donor in A. woodii.

\begin{tabular}{|c|c|c|c|c|}
\hline \multirow[t]{2}{*}{ Product } & \multirow[t]{2}{*}{ Key enzymes/intermediates } & \multirow[t]{2}{*}{ Conversion (acetyl-CoA as precursor) } & \multicolumn{2}{|c|}{ ATP yield } \\
\hline & & & $\mathrm{H}_{2}+\mathrm{CO}_{2}$ & CO \\
\hline Acetate & Acetate kinase & acetyl-CoA $\rightarrow$ acetate & 0.3 & 1.5 \\
\hline \multirow[t]{2}{*}{ Ethanol } & $\mathrm{AIDH} / \mathrm{ADH}$ & acetyl-CoA $\rightarrow$ ethanol & -0.1 & 1.7 \\
\hline & $\mathrm{AOR}+\mathrm{ADH}$ & & 0.3 & 2.1 \\
\hline \multirow[t]{4}{*}{ Butanol } & $\mathrm{BDH}$ & 2 acetyl-CoA $\rightarrow$ butanol & -0.2 & 3.4 \\
\hline & $\mathrm{BDH}$, bifurcating Bcd & & 0.4 & 4.0 \\
\hline & AOR & & 0.2 & 3.8 \\
\hline & AOR, bifurcating Bcd & & 0.8 & 4.4 \\
\hline Isoprene & Mevalonate & 3 acetyl-CoA $\rightarrow$ isoprene $+\mathrm{CO}_{2}$ & -4.5 & -0.3 \\
\hline \multirow[t]{2}{*}{ Lactate } & NADH-dependent LDH & acetyl-CoA $+\mathrm{CO}_{2} \rightarrow$ lactate & -0.7 & 1.1 \\
\hline & Bifurcating LDH & & -0.1 & 1.7 \\
\hline 2,3-Butanediol & Acetolactate synthase & 2 acetyl-CoA $\rightarrow 2,3$-butanediol & -1.7 & 1.6 \\
\hline Acetone & Acetoacetate & 2 acetyl-CoA $\rightarrow$ acetone $+\mathrm{CO}_{2}$ & -0.4 & 2.0 \\
\hline Isobutene & Acetone, 3-OH-isovalerate & 3 acetyl-CoA $\rightarrow$ isobutene $+2 \mathrm{CO}_{2}$ & -2.1 & 1.5 \\
\hline
\end{tabular}

by a lactate dehydrogenase (LDH) (Gladden, 2004). A. woodii has an electron-bifurcating lactate dehydrogenase (bLDH), which increases the amount of ATP produced via chemiosmosis (Weghoff et al., 2015). Even if a bifurcating LDH is involved, production of lactate from $\mathrm{H}_{2}+\mathrm{CO}_{2}$ still requires energy in $A$. woodii or C. autoethanogenum by -0.1 or $-0.2 /-0.7$ ATP/lactate (depending on the MTHFR reaction) and, thus lactate production from $\mathrm{H}_{2}+\mathrm{CO}_{2}$ is not possible (Tables 1, 2). However, if an electron-bifurcating MTHFR is assumed, lactate production with or without a bifurcating $\mathrm{LDH}$ from $\mathrm{H}_{2}+$ $\mathrm{CO}_{2}$ is possible ( 0.2 or $0.8 \mathrm{ATP} /$ lactate) in C. autoethanogenum (Table 2). If $\mathrm{CO}$ is used as electron donor, the production of lactate with $A$. woodii or $C$. autoethanogenum will always gain ATP, independent of any electron bifurcation event (MTHFR, bLDH) (Tables 1, 2). Due to the energetics, A. woodii can not produce lactate from $\mathrm{H}_{2}+\mathrm{CO}_{2}$ (Schoelmerich et al., 2018). In contrast, $C$. autoethanogenum has been shown to produce lactate from syngas (Köpke et al., 2011b; Liew et al., 2017).

For the production of butanol, 2 molecules of acetyl-CoA are required (Dürre et al., 1992). Two molecules of acetylCoA are condensed to acetoacetyl-CoA which is reduced to 3hydroxypropionyl-CoA with NADH (Figure 6). After water is split off, crotonyl-CoA is reduced to butyrate by a butyryl-CoA dehydrogenase $(\mathrm{Bcd})$. Due to the relative positive redox potential of the crotonyl-CoA/butyryl-CoA couple $\left(\mathrm{E}_{0^{\prime}}=-10 \mathrm{mV}\right)$, $\mathrm{NADH}$-dependent Bcds can couple crotonyl-CoA reduction to ferredoxin reduction (bBcD) ( $\mathrm{Li}$ et al., 2008). If the $\mathrm{Bcd}$ is not electron bifurcating, the pathway requires $4 \mathrm{NADH}$ and yields 1.2 ATP/butanol for A. woodii or 1.6/2.2 ATP/butanol for $C$. authoethanogenum (depending on the MTHFR reaction). If the $\mathrm{Bcd}$ is electron bifurcating, the additional conservation of energy via the Rnf complex leads to a total ATP yield of 1.8 ATP/butanol for A. woodii or 2.6/3.2 ATP/butanol for C. authoethanogenum (depending on the MTHFR reaction). Since 1.4 ATP in A. woodii or 1.2 ATP in C. authoethanogenum have to be invested to supply 2 acetyl-CoA, the butanol production from $\mathrm{H}_{2}+\mathrm{CO}_{2}$ via butyraldehyde dehydrogenase is only possible, if a bifurcating Bcd is involved (Tables 1, 2). In case of C. authoethanogenum the energetics for butanol production from $\mathrm{H}_{2}+\mathrm{CO}_{2}$ without a bifurcating Bcd (0.2 ATP/butanol) only gains ATP, if an electronbifurcating MTHFR is assumed (Table 2).

Butanol production can also be achieved by reducing butyrate to butyraldehyde (Nissen and Basen, 2019). AORs have been shown to reduce a broad range of acids to the corresponding aldehydes, also the reduction of butyrate to butyraldehyde ( $\mathrm{Ni}$ et al., 2012; Perez et al., 2013). The requirement of $\mathrm{Fd}^{2-}$ reduces the energy yield via chemiosmosis, but the formation of butyrate from butyryl-CoA yields 1 ATP via substrate-level phosphorylation. Butanol production via AORs is energetically possible for $A$. woodii and $C$. authoethanogenum independent on the pathway and electron bifurcation ( $\mathrm{bBcD}, \mathrm{MTHFR})$ (Tables 1, 2). With CO as electron donor, production of butanol will be, in any case, strongly energy positive, yielding 3.4-4.4 ATP/butanol for A. woodii (depending on the pathway) or 2.83.8/3.3-4.3 ATP/butanol for C. authoethanogenum (depending on the pathway/ MTHFR reaction) (Tables 1, 2).

For the production of 2,3-butanediol, 2 pyruvate are condensed and decarboxylated, yielding acetolactate (Figure 6; Hess et al., 2015). This is further decarboxylated, giving rise to acetoin. The reduction of acetoin with NADH yields 2,3-butanediol. In sum, 2 acetyl-CoA are reduced with $2 \mathrm{Fd}^{2-}$ and $2 \mathrm{NADH}$ to 2,3-butanediol. The use of $\mathrm{H}_{2}$ or $\mathrm{CO}$ as external electron donor makes big differences in the energy balance: with $\mathrm{H}_{2}$, in A.woodii 1.7 ATP have to be invested for the synthesis of one 2,3-butanediol, with CO 1.6 ATP are produced for every 2,3-butanediol synthesized (Table 1). Using $\mathrm{H}_{2}$ as electron donor in C. authoethanogenum 2,3-butanediol production is not possible, even if the MTHFR is electron bifurcating, because the ATP/2,3-butanediol ratio is strongly ATP-dependent with -1.8/-1.2 ATP/2,3-butanediol (depending 
TABLE 2 | ATP yield for the synthesis of products from acetyl-CoA with $\mathrm{H}_{2}+\mathrm{CO}_{2}$ or $\mathrm{CO}$ as electron donor in $\mathrm{C}$. autoethanogenum.

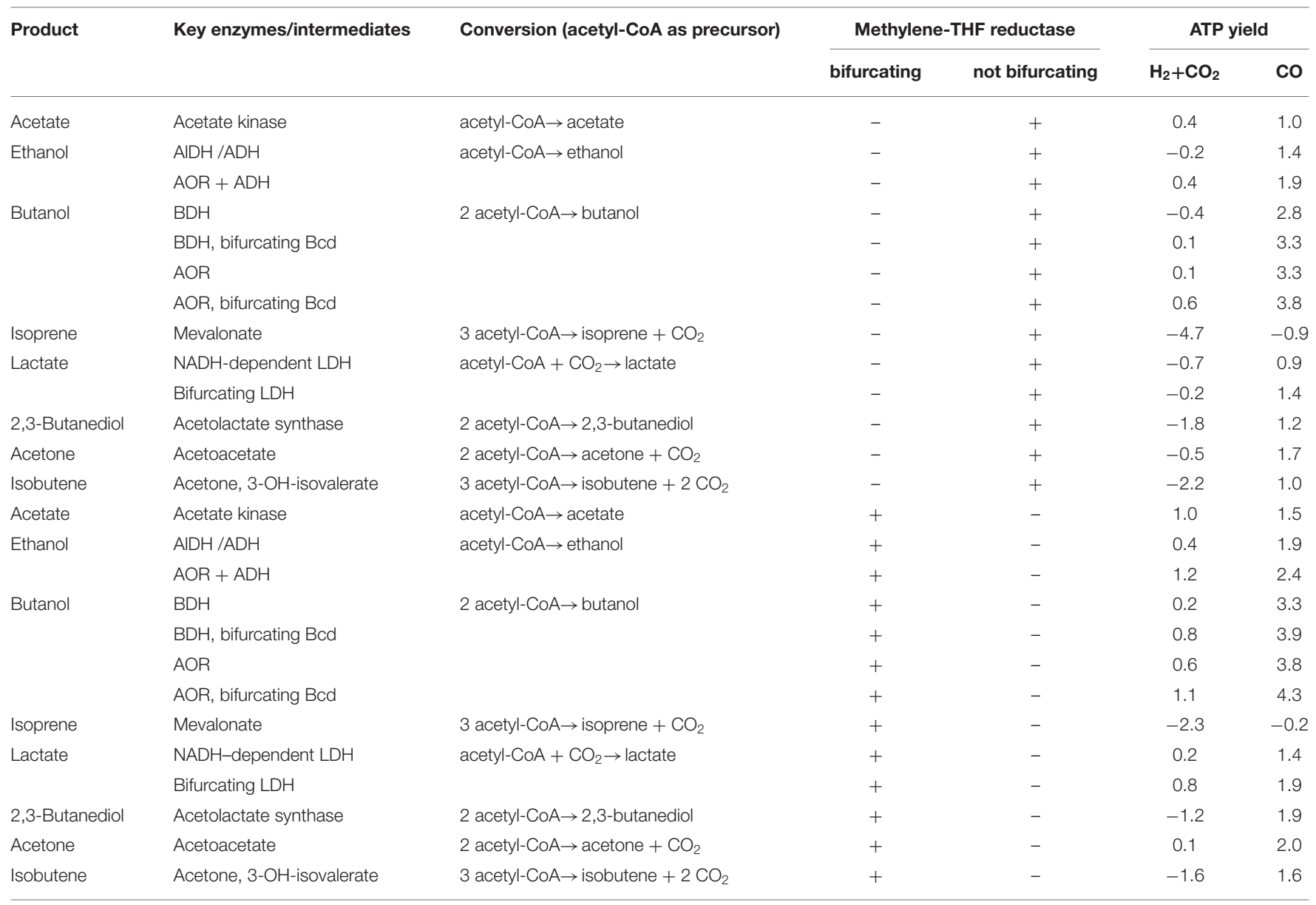

on the MTHFR reaction) (Table 2). Again, the energetic favorable reduction power of $\mathrm{CO}$ enhances the ATP yield also during 2,3butanediol fermentation (1.2/1.9 ATP/2,3-butanediol; depending on the MTHFR reaction), which makes the production of 2,3-butanediol in C. authoethanogenum possible (Köpke et al., 2011b).

Recently, A. woodii was shown to produce acetone from $\mathrm{H}_{2}+\mathrm{CO}_{2}$ after implementation of the corresponding pathway from Clostridium acetobutylicum, but only as a side product in small amounts (Hoffmeister et al., 2016). During the production of acetone 2 acetyl-CoA are condensed to acetoacetyl-CoA, which is further converted to acetoacetate and then to acetone (Figure 6; Dürre et al., 1992). The production of acetone from $\mathrm{H}_{2}+\mathrm{CO}_{2}$ by $A$. woodii would require an input of ATP (-0.4 ATP/acetone), while production from CO would be coupled to ATP production (2.0 ATP/acetone) (Table 1). In comparison, acetone production from $\mathrm{H}_{2}+\mathrm{CO}_{2}$ by $C$. authoethanogenum is possible, if an electron-bifurcating MTHFR is assumed (Table 2). The overall ATP/acetone yield is in this case positive, with 0.1 ATP per produced acetone (Table 2). With CO, C. authoethanogenum has an even better ATP yield with 1.7/2.0 ATP/acetone (depending on the MTHFR reaction) (Table 2).
Acetone can be a precursor for further products. For example, for the production of isobutene (Figure 6; van Leeuwen et al., 2012). With the patented enzyme system for the acetylation of acetone to 3-hydroxy-isovalerate, followed by the ATP-dependent decarboxylation, isobutene could be produced in microorganisms (van Leeuwen et al., 2012). Because an even higher ATP investment is necessary, compared to the production of acetone, the energetics for $A$. woodii or $C$. authoethanogenum with $\mathrm{H}_{2}+\mathrm{CO}_{2}$ as substrate are much worse (Tables 1, 2). The production of isobutene from $\mathrm{H}_{2}$ $+\mathrm{CO}_{2}$ by $A$. woodii would require an input of ATP $(-2.1$ $\mathrm{ATP} /$ isobutene), while production from $\mathrm{CO}$ would be coupled to ATP production (1.5 ATP/isobutene) (Table 1). Using $C$. authoethanogenum for the production of isobutene, an input of ATP of $-2.2 /-1.6$ per isobutene (depending on the MTHFR reaction) with $\mathrm{H}_{2}+\mathrm{CO}_{2}$ is needed (Table 2). With $\mathrm{CO}$ as electron donor, C. authoethanogenum has an ATP gain with 1.0/1.6 ATP/isobutene (depending on the MTHFR reaction) (Table 2).

The production of isoprene is even more energy consuming. To produce isoprene a non-mevalonate pathway has been engineered in acetogens (Diner et al., 2018). The mevalonate pathway starts with the condensation of 2 
acetyl-CoA to acetoacetyl-CoA (Figure 6). The addition of a third acetyl-CoA yields 3-hydroxy-3-methyl-glutarylCoA (HMG-CoA), which is reduced by a $\mathrm{NAD}^{+}$-dependent HMG-CoA reductase to mevalonate. After two consequent ATP-dependent phosphorylations, diphosphomevalonate is decarboxylated at the expense of ATP, giving rise to isopentenyl diphosphate (IPP) (Kuzuyama, 2002). After an isomerization, the diphosphate bond is hydrolyzed, yielding isoprene. Thus, in total, the conversion of 3 acetyl-CoA to isoprene requires $2 \mathrm{NADPH}$ and 3 ATP. Because of the high energy input needed, both $A$. woodii or $C$. authoethanogenum have an ATP-demand per produced isoprene when growing on $\mathrm{H}_{2}$ $+\mathrm{CO}_{2}$ or $\mathrm{CO}$ as substrate under all possible scenarios (Tables 1, 2).

\section{OVERCOMING ENERGETIC BARRIERS}

The reduction of $\mathrm{CO}_{2}$ with $\mathrm{H}_{2}$ or with $\mathrm{CO}$ as reductant is energetically limited and currently only two products, ethanol and acetate can be produced with high titers on an industrial scale (Daniell et al., 2012; Bengelsdorf et al., 2018). As outlined above, ethanol formation from $\mathrm{H}_{2}+\mathrm{CO}_{2}$ via acetyl-CoA to acetaldehyde and ethanol requires the net input of ATP and should not be possible with high specificity. However, it is possible in some species, and these species have an enzyme that activates acetate $\left(\Delta \mathrm{G}^{0^{\prime}}=-15.4 \mathrm{~kJ} / \mathrm{mol}\right)$ with reduced ferredoxin as electron donor, the aldehyde:ferredoxin oxidoreductase (AOR) (White et al., 1989; Chan et al., 1995; Heider et al., 1995; Nissen and Basen, 2019). Therefore, ethanol formation still includes the acetate kinase reaction. Although additional reduced ferredoxin is required as driving force and thus missing as driving force for ATP synthesis, the overall process yields $1.2 \mathrm{ATP} / \mathrm{mol}$ ethanol. Acetogens like $A$. woodii that do not have an AOR do not produce ethanol from $\mathrm{H}_{2}+\mathrm{CO}_{2}$, but with the advent of genetic methods in acetogens, implementing an AOR into the acetogenic metabolism would be the first choice to increase the energetics and overcome the energetic barrier to acetyl-CoA formation. In contrast, $C$. autoethanogenum produces ethanol from $\mathrm{H}_{2}+$ $\mathrm{CO}_{2}$ (Mock et al., 2015; Liew et al., 2017). The importance of AOR enzymes for higher ethanol production rates were shown, for example, in Pyrococcus furiosus or C. authoethanogenum (Basen et al., 2014; Liew et al., 2017). An engineered $P$. furiosus strain converted glucose to ethanol via acetate and acetaldehyde, catalyzed by the host-encoded aldehyde ferredoxin oxidoreductase (AOR) and heterologously expressed AdhA, in an energy-conserving, redox-balanced pathway (Basen et al., 2014; Müller, 2014). Implementing an indirect ethanol pathway by deletion of $A d h E$ in the genome of $C$. authoethanogenum shifted the conversion of acetate to acetaldehyde via AOR (Liew et al., 2017). Using this strategy the generated strains produced up to $180 \%$ more ethanol and also accumulated up to $38 \%$ less of acetate. The first heterologous AOR production in an acetogenic bacterium was recently described for Clostidium carboxidivorans (Cheng et al., 2019). A plasmid-based implementation of the AOR genes lead to higher ethanol production rates during growth on glucose. Furthermore strains overexpressing AOR showed $\mathrm{CO}_{2}$ re-assimilation during heterotrophic growth on glucose (Cheng et al., 2019). However, the selectivity of AORs to reduce short chain fatty acids, like acetate, can also easily be achieved with simple changes in growth conditions (Abubackar et al., 2015; Mock et al., 2015; Martin et al., 2016; Richter et al., 2016a,b). For syngas-fermenting bacteria, that are using the AOR-ADH pathway, solventogenesis (alcohol production) occurs preferably when growth is limited due to nutrient limitations or at low pH (Daniell et al., 2012; Abubackar et al., 2015; Mock et al., 2015; Al-Shorgani et al., 2018). For example, results from bioreactor studies with continuous $\mathrm{CO}$ supply revealed that the shift from high to low $\mathrm{pH}$ values improves ethanol production by $C$. autoethanogenum without any accumulation of acetic acid (Abubackar et al., 2015). Low pH is therefore not only beneficial for ethanol production via syngas fermentation, but also an effective method for decreasing acetate concentration in the fermentation broth (Abubackar et al., 2015; Martin et al., 2016; Richter et al., 2016a).

The same principle would also apply to other alcohols. Butanol is an interesting biofuel and can be produced by acetogens from the condensation of two mol acetyl-CoA to acetoacetyl-CoA followed by a reduction to butyryl-CoA, via a series of reactions known from fatty acid oxidation (see above) (Dürre, 2007; Köpke et al., 2011c). Butyryl-CoA can be either oxidized to butyrate giving one ATP or reduced to butanol without the production of an ATP. In this pathway, the acetate kinase-produced ATP's (2 molecules) are missing and although one ATP is gained by the butyrate kinase, the overall ATP gain is negative and butyrate cannot be produced from $\mathrm{H}_{2}+\mathrm{CO}_{2}$. With $\mathrm{CO}$ as substrate the energetics are a bit better. The oxidation of $\mathrm{CO}$ is coupled to more ferredoxin reduction, which can be used as driving force to produce additional ATP. But butanol is not produced for energetic reasons, since a redirection of butyryl-CoA to butanol results in a loss of another ATP. Here, implementation of an AOR by genetic engineering would bring the energetics over the hurdle to produce butanol (Ni et al., 2012; Perez et al., 2013). AORs so far characterized are rather unspecific and can oxidize chain aldehydes (e.g., formaldehyde, acetaldehyde, crotonaldehyde), branched chain aldehydes (e.g., isovalerylaldehyde) as well as aromatic aldehydes (phenylacetaldehyde, benzaldehyde) or reduce acetate and butyrate (Nissen and Basen, 2019). The specificity and efficiency of the AOR could be improved by directed evolution (Turner, 2003; Dalby, 2011).

As outlined above, energy conservation during acetogenesis from $\mathrm{H}_{2}+\mathrm{CO}_{2}$ involves substrate level phosphorylation as well as electron transport phosphorylation. The former yields one ATP per acetate, the latter much less, in the order of 0.3 and less per mol of acetate. So far, every acetogen examined has only one of the two respiratory enzymes, Ech (Schoelmerich and Müller, 2019) or Rnf (Biegel et al., 2011). Interestingly, Ech complexes have thus far only been found in thermophilic species (Schoelmerich and Müller, 2019). One idea to improve the energetics is to implement by genetic engineering an Ech complex into A. woodii, C. autoethanogenum or others, but this requires an Ech complex from a mesophilic 
bacterium. Fortunately, Ech-containing mesophilic anaerobes do exist, for example in the Butyrivrio clade (Figure 7; Hackmann and Firkins, 2015; Schoelmerich et al., 2020). Currently, it is tested whether these can be functionally produced in A. woodii. Another obstacle is that $A$. woodii uses $\mathrm{Na}^{+}$as coupling ion for the ATP synthase and the Rnf complex (Hess et al., 2013b; Matthies et al., 2014); ideally, the Ech complex implemented should also translocate $\mathrm{Na}^{+}$but so far, the ion specificity of these Ech complexes as well as others is not known, simply due to the fact that they have never been purified and reconstituted into liposomes. However, even if an Ech complex is a proton and not a sodium ion pump, the proton gradient established would be converted to a Na${ }^{+}$gradient by a Na${ }^{+} / \mathrm{H}^{+}$antiporter present in A. woodii (Biegel and Müller, 2011). The same principle could be used vice versa, but this would require a thermophilic Rnf complex, for example from Thermotoga maritima (Kuhns et al., 2020).

Membrane-bound cytochromes are well-known electron carriers in membrane-bound electron transport chains; their presence would immediately suggest an electron transport chain and electron transport phosphorylation in the organism they have been discovered in (Gottwald et al., 1975; Das et al., 1989; Das and Ljungdahl, 2003). Methanogenic archaea also use the Wood-Ljungdahl pathway for $\mathrm{CO}_{2}$ fixation and methane formation but how this is coupled to energy conservation has been hotly debated a while ago (Blaut and Gottschalk, 1984; Lancaster, 1989). Some favored substrate level phosphorylation by an unknown reaction in the WLP, other some sort of to be discovered electron transport phosphorylation. The discovery of b559-type cytochromes in M. barkeri in 1979 by Kühn and Gottschalk was a ground-breaking study that excited the entire field and paved the road to the discovery of electron transport phosphorylation in this model methanogen (Kühn et al., 1979; Blaut and Gottschalk, 1984). Later, methanophenazine (Abken et al., 1998) was found as additional electron carrier in these cells and the heterodisulfide reductase as electron acceptor (Bäumer et al., 1998). Now, different electron transport chains with different electron input modules in different methanogens are well-established (Deppenmeier, 2002; Schlegel and Müller, 2013; Welte and Deppenmeier, 2014). In this historic context was the discovery of $b$-type cytochromes in $M$. thermoacetica in 1975 by Gottwald et al. That was immediately taken as indication for cytochrome-dependent electron transport chain as part of a chemiosmotic mechanism of ATP synthesis. Later, reduction of cytochromes as well as the concomitant generation of a membrane potential in vesicles of $C$. thermoautotrophicum was detected (Hugenholtz and Ljungdahl, 1989). The most conclusive evidence that the cytochromes are involved in coupling the WLP to energy conservation was presented by Kamlage and Blaut (1993). By showing that a cytochrome-deficient mutant was no longer able to oxidize methyl groups to $\mathrm{CO}_{2}$ or reduce $\mathrm{CO}_{2}$ to the level of a methyl group, they laid the foundation that cytochromes are involved as electron carriers in the methylene-THF reductase, a reaction that was already postulated in 1977 by Thauer et al. (1977) to be the most likely energy conserving site since reduction of methylene-THF to Methyl-THF $\left(\Delta \mathrm{G}^{0^{\prime}}=-23.1 \mathrm{~kJ} / \mathrm{mol}\right)$ with $\mathrm{NAD}^{+}$as reductant is the most exergonic of the pathway. An involvement of cytochromes in $\mathrm{CO}_{2}$ reduction is also supported by the finding that nitrate, an alternative electron acceptor in $M$. thermoacetica, represses the synthesis of the $b$-type cytochrome (Fröstl et al., 1996; Arendsen et al., 1999). An involvement of cytochromes in the methylene-THF reductase reaction was also very recently speculated by Keller et al. (2019) for Thermacetogenium phaeum. However, it is far from being settled whether or not there is indeed a third, cytochrome-dependent respiratory chain in addition to Ech- and Rnf-containing respiratory chains in acetogens. This must be addressed in future studies using the genetic tools that have been developed. However, it should be noted that Rnf- and Ech-acetogens such as A. woodii and T. kivui do not have cytochromes (Müller, 2003). Others seem to have Rnf plus cytochromes such as Sporomusa (Kamlage et al., 1993; Poehlein et al., 2013) or Clostridium aceticum (Poehlein et al., 2015) or Ech plus cytochromes such as M. thermoacetica (Gottwald et al., 1975; Pierce et al., 2008). Important for the context here is, that the current industrially relevant cells do not have cytochromes. However, implementing cytochromes by genetic engineering is not an easy task since a rather extensive biogenesis machinery as well as genes encoding biosynthesis of quinones are required (Thöny-Meyer, 1997).

In addition to $\mathrm{CO}_{2}$, some acetogens can reduce a number of alternative substrates such as pyruvate (Misoph and Drake, 1996), fumarate (Dorn et al., 1978; Matthies et al., 1993), aromatic acrylates (Bache and Pfennig, 1981; Tschech and Pfennig, 1984; Misoph et al., 1996), inorganic sulfur compounds (Beaty and Ljungdahl, 1990, 1991; Hattori et al., 2000), and nitrate or nitrite (Seifritz et al., 1993, 2003; Fröstl et al., 1996; Arendsen et al., 1999). For industrial applications, the electron acceptor would have to be added as well as the product removed from the fermenter, thus raising the costs of operation and the price of the product. Of these alternative electron acceptors, the use of aromatic acrylates, nitrate and nitrite have been studied to some extent (Bache and Pfennig, 1981; Tschech and Pfennig, 1984; Seifritz et al., 1993, 2003; Fröstl et al., 1996; Arendsen et al., 1999). Aromatic acrylates such as caffeate are reduced by $A$. woodii simultaneously with $\mathrm{CO}_{2}$ when $\mathrm{H}_{2}$ or fructose is the electron donor, or sequential with $\mathrm{CO}_{2}$ first, when methanol is the electron donor (Dilling et al., 2007). Caffeate respiration is linked to energy conservation via Rnf and ATP synthase and co-utilization of caffeate and $\mathrm{CO}_{2}$ would enhance the ATP level (Imkamp and Müller, 2002; Hess et al., 2013a). However, caffeate is rather toxic and cells do not tolerate more than $\sim$ $5 \mathrm{mM}$ (Parke and Ornston, 2004), which, in addition to the costs, makes the approach economically less favorable. Nitrate is rather inexpensive but the effect of nitrate is discussed very controversially. Under heterotrophic conditions, nitrate is stimulatory but lithotrophic growth of $M$. thermoacetica is inhibited (Seifritz et al., 2002). The basis for this inhibition remains to be elucidated, one study argues that the activity of enzymes of the WLP is not altered but only cytochromes disappear (Fröstl et al., 1996) whereas the other argues that also the activities of key enzymes are down regulated by nitrate (Arendsen et al., 1999). Mechanistically, it is not known 


\section{Pseudobutyrivibrio Ruminis DSM9787 (IE20DRAFT_1834-1839)}

\section{Butyrivibrio proteoclasticus B316} (bpr_I1404-1409)

\section{Pseudobutyrivibrio xylanivorans DSM 10317 (EJ90DRAFT_01621-01626)}

\author{
Butyrivibrio fibrisolvens DSM 3071 \\ (EJ22DRAFT_01569-01574)
}

Methanosarcina mazei 1.H.T.2.3 (Ga0106563_102614-102619)

Methanosarcina barkeri DSM 804 (Mbar_A0147-A0152)
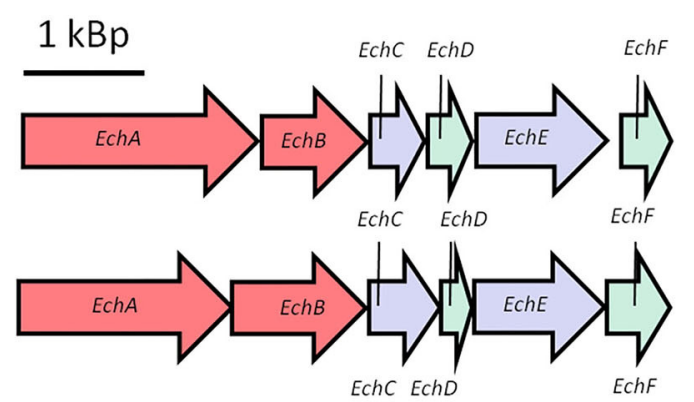

EchC EchD EchF
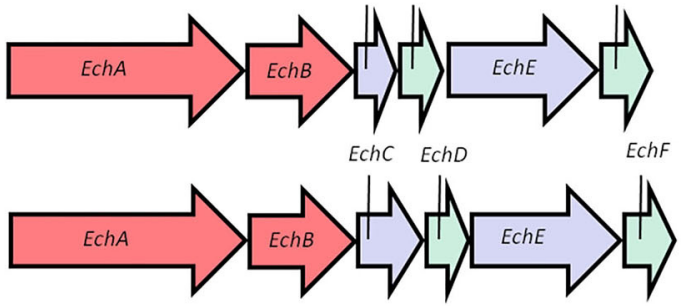

EchC EchD
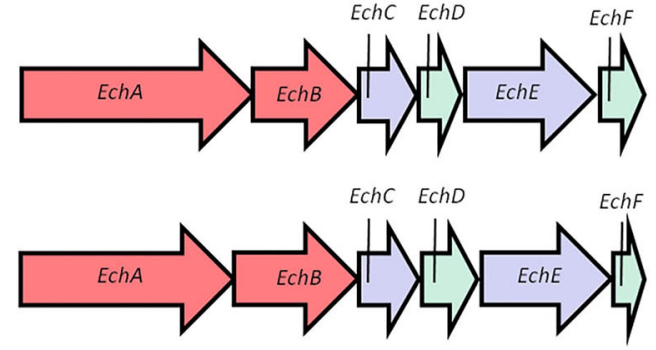

FIGURE 7 | Ech gene-cluster of representative mesophilic anaerobes. Ech genes are highly distributed in the mesophilic Butyrivibrio clade. Typical anaerobes are for example Pseudobutyrivibrio ruminis, Butyrivibrio proteoclasticus, Pseudobutyrivibrio xylanivorans or Butyrivibrio fibrisolvens. Here shown are the Ech gene-cluster-comparison against representative archea M. mazei and M. barkeri. Ech gene-cluster of mesophilic anaerobes show similar genetic organization.

whether nitrate reduction is coupled to energy conservation via a nitrate-dependent ion-motive respiratory chain or whether the presence of nitrate redirects electrons to the Rnf- and Echcomplexes thus providing more fuel for chemiosmotic ATP synthesis. In contrast, C. ljungdahlii co-utilized $\mathrm{CO}_{2}$ and nitrate and this enhanced biomass formation from $\mathrm{H}_{2}+\mathrm{CO}_{2}$ (Emerson et al., 2019). Unfortunately, ethanol production from $\mathrm{H}_{2}+\mathrm{CO}_{2}$ was strongly inhibited by nitrate, indicating that the electron from acetyl-CoA reduction to ethanol goes to nitrate. However, in $\mathrm{pH}$-controlled bioreactors nitrate improved growth and ethanol formation but resulted in stochastic inhibition events (Klask et al., 2020). Clearly, more basic research has to be done on nitrate reduction and its possible coupling to energy conservation and in addition, one has to remember that nitrate reduction is only observed in a few species and, for example, not in A. woodii.

So far, we have discussed alterations in the pathway of carbon and electrons in acetogenesis from $\mathrm{H}_{2}+\mathrm{CO}_{2}$ or $\mathrm{CO}$ to increase chemiosmotic ATP synthesis. An alternative is to bring in a reaction (sequence) that is coupled to substrate level phosphorylation. To phosphorylate ADP the reaction must have a phosphoryl group transfer potential that is more negative than $-31.8 \mathrm{~kJ} / \mathrm{mol}$ (Thauer et al., 1977). This restricts the reactions to only a few:
Creatine kinase:

$$
\begin{gathered}
\text { creatinephosphate }+\mathrm{H}_{2} \mathrm{O} \rightarrow \text { creatine }+\mathrm{P}_{\mathrm{i}} \\
\left(\Delta \mathrm{G}^{0^{\prime}}=-43.3 \mathrm{~kJ} / \mathrm{mol}\right)
\end{gathered}
$$

Arginine kinase:

$$
\begin{gathered}
\text { argininephosphate }+\mathrm{H}_{2} \mathrm{O} \rightarrow \text { arginine }+\mathrm{P}_{\mathrm{i}} \\
\left(\Delta \mathrm{G}^{0^{\prime}}=-45.0 \mathrm{~kJ} / \mathrm{mol}\right)
\end{gathered}
$$

Carbamate kinase:

$$
\begin{gathered}
\text { carbamylphosphate }+\mathrm{H}_{2} \mathrm{O} \rightarrow \text { carbamate }+\mathrm{P}_{\mathrm{i}} \\
\left(\Delta \mathrm{G}^{0^{\prime}}=-39.3 \mathrm{~kJ} / \mathrm{mol}\right)
\end{gathered}
$$

Succinyl-CoA synthetase:

$$
\begin{aligned}
& \text { succinyl }-\mathrm{CoA} \rightarrow \text { succinate }+\mathrm{HS}-\mathrm{CoA} \\
&\left(\Delta \mathrm{G}^{0^{\prime}}=-27.0 \mathrm{~kJ} / \mathrm{mol}\right)
\end{aligned}
$$


Acetate kinase:

$$
\begin{gathered}
\text { acetylphosphate }+\mathrm{H}_{2} \mathrm{O} \rightarrow \text { acetate }+\mathrm{P}_{\mathrm{i}} \\
\left(\Delta \mathrm{G}^{0^{\prime}}=-44.8 \mathrm{~kJ} / \mathrm{mol}\right)
\end{gathered}
$$

Butyrate kinase:

$$
\begin{gathered}
\text { butyrylphosphate }+\mathrm{H}_{2} \mathrm{O} \rightarrow \text { butyrate }+\mathrm{P}_{\mathrm{i}} \\
\left(\Delta \mathrm{G}^{0^{\prime}}=-35.6 \mathrm{~kJ} / \mathrm{mol}\right)
\end{gathered}
$$

Phosphoglycerate kinase:

$$
\begin{aligned}
& 1,3 \text { - bisphosphoglycerate }+\mathrm{H}_{2} \mathrm{O} \rightarrow 3-\text { phosphoglycerate } \\
&+\mathrm{P}_{\mathrm{i}} \\
&\left(\Delta \mathrm{G}^{0^{\prime}}=-51.9 \mathrm{~kJ} / \mathrm{mol}\right)
\end{aligned}
$$

Pyruvate kinase:

$$
\begin{gathered}
\text { phosphoenolpyruvate }+\mathrm{H}_{2} \mathrm{O} \rightarrow \text { pyruvate }+\mathrm{P}_{\mathrm{i}} \\
\left(\Delta \mathrm{G}^{0^{\prime}}=-51.6 \mathrm{~kJ} / \mathrm{mol}\right)
\end{gathered}
$$

Arginine kinase and creatine kinase (equation 3 and 4) play an essential role in ATP buffering systems in invertebrates (Wallimann et al., 1992) and are not useful here since they require previous activation of the substrate by ATP. Reaction 4 is part of the arginine deaminase pathway, a pathway found in eukaryotes (Novak et al., 2016) as well as prokaryotes (Deibel, 1964) that provide ATP from a fermentative pathway. In that pathway arginine is converted to ornithine, ammonium, and $\mathrm{CO}_{2}$, while generating ATP from ADP and phosphate. The enzymes involved in the three steps of the pathway are arginine deiminase (ADI) (Petrack et al., 1957), ornithine transcarbamylase (OTC) (Kalman et al., 1965; Hernandez and Johnson, 1967), and carbamate kinase (CK) (Grisolia et al., 1962). The first reaction, catalyzed by $\mathrm{ADI}$, is the deamination of arginine to yield citrulline and $\mathrm{NH}_{4}^{+}$(Petrack et al., 1957). OTC then catalyzes the conversion of citrulline and inorganic phosphate into carbamoylphosphate and ornithine (Kalman et al., 1965; Hernandez and Johnson, 1967). Finally, CK catalyzes the hydrolysis of carbamoyl phosphate to form $\mathrm{CO}_{2}$ and $\mathrm{NH}_{4}^{+}$, while the phosphate group is used to regenerate ATP from ADP (Grisolia et al., 1962). Indeed, feeding arginine $(20 \mathrm{mM})$ promoted growth advantages in A. woodii (Beck et al., 2020). A $69 \%$ higher maximal $\mathrm{OD}_{600}$ and about $60 \%$ lower acetate yield per biomass was obtained in the presence of arginine (Beck et al., 2020). However, the costs of arginine and the removal of ornithine and ammonium have to be considered. Succinly-CoA synthetase is a reaction of the tricarbonic acid cycle (TCC) (Hager, 1962); this could be useful by feeding citrate which is converted by the enzymes of the TCC to succinate. Uptake of citrate (Dimroth and Thomer, 1986) and export of succinate (Kimmich et al., 1991) must be ensured by the appropriate transporter; another disadvantage is that the reaction sequence requires four electrons (2 NADH). Acetate kinase and butyrate kinase have been discussed above as part of the butyrate/butanol pathway. Intermediates of this pathway are CoA esters, which are expensive, instable and probably not taken up (Banis et al., 1976). Feeding the precursors acetate or acetoacetate would require an ATP-dependent activation, so that the net ATP gain by SLP would be zero.

An additional strategy is to provide organic electron donors that are acetogenic substrates. It is known for some acetogens that they can utilize different substrates simultaneously, for example $\mathrm{H}_{2}+\mathrm{CO}_{2}$ together with glucose (Braun and Gottschalk, 1981). The WLP is ideally suited for capturing $\mathrm{CO}_{2}$ to increase the product yields. Homoacetogenesis according to equation 11 and 12 can be regarded as mixotrophic growth: sugar is oxidized to acetate giving rise to ATP synthesis by the reactions of pyruvate kinase, phosphoglycerate kinase and acetate kinase.

$$
\begin{aligned}
\text { glucose }+4 \mathrm{ADP} & +4 \mathrm{P}_{\mathrm{i}} \rightarrow 2 \text { acetate }+2 \mathrm{CO}_{2} \\
& +4 \mathrm{ATP}+2 \mathrm{H}_{2} \mathrm{O}+8[\mathrm{H}]
\end{aligned}
$$

$$
\begin{aligned}
8[\mathrm{H}]+2 \mathrm{CO}_{2} & +x A D P+x P_{i} \rightarrow \text { acetate } \\
& +2 \mathrm{H}_{2} \mathrm{O}+x \text { ATP }
\end{aligned}
$$

The electrons gained during glycolysis are captured by $\mathrm{CO}_{2}$ reduction (Schuchmann and Müller, 2016). Alternatively, interspecies $\mathrm{H}_{2}$ transfer can be used instead of the WLP to get rid of surplus reducing equivalents as shown for $A$. woodii (Winter and Wolfe, 1980; Wiechmann et al., 2020) or T. kivui (Moon et al., 2020). In principle any oxidative pathway can be hooked up to the WLP; this is what makes the WLP and acetogens so interesting for biotechnology. On the downside, mixotrophy is limited by the redox balance (Schuchmann and Müller, 2016). Reduction of $2 \mathrm{CO}_{2}$ to acetate requires 8 electrons. Therefore, the first requirement for a pathway coupled to the WLP is the release of 8 electrons per $2 \mathrm{CO}_{2}$ produced to allow complete $\mathrm{CO}_{2}$ fixation. This is the case for oxidation of glucose to 2 acetate by typical fermentations (Schuchmann and Müller, 2016). However, this approach is limited to end products with the same oxidation state as acetate, since glucose oxidation does not provide enough electrons. Electron limitation can be overcome by supplying additional electron donors such as $\mathrm{H}_{2}$ or electrons provided by a cathode for direct electron uptake (Bajracharya et al., 2015; Philips, 2020). In this case, $\mathrm{H}_{2}$ provides an unlimited source of reducing power (Liu and Suflita, 1995). Under these conditions, ethanol production from glucose and $\mathrm{H}_{2}$ according to equation 13 is possible.

$$
\begin{aligned}
\text { glucose }+6 \mathrm{H}_{2} & \rightarrow 3 \text { ethanol }+3 \mathrm{H}_{2} \mathrm{O} \\
\left(\Delta \mathrm{G}^{0^{\prime}}\right. & =-337 \mathrm{~kJ} / \mathrm{mol})
\end{aligned}
$$

Other examples of acetogenic substrates are primary (Eichler and Schink, 1984, 1985) and secondary alcohols (Zellner and Winter, 
1987). Oxidation of ethanol under anaerobic conditions is only possible by specialized bacteria or archaea that either transfer the electrons to $\mathrm{H}_{2}$ which is then used by a syntrophic partner or to an electron acceptor such as $\mathrm{CO}_{2}$ or sulfate (Eichler and Schink, 1985; Seitz et al., 1990; Schink and Friedrich, 1994; Schink, 1997). Butandiol oxidation requires the presence of $\mathrm{CO}_{2}$ according to equation 14 .

$$
\begin{aligned}
42,3 \text { - butanediol }+6 \mathrm{CO}_{2} & +5.3 \mathrm{ADP}+5.3 \mathrm{P}_{\mathrm{i}} \rightarrow 11 \text { acetate } \\
& +5.3 \mathrm{ATP}+3.3 \mathrm{H}_{2} \mathrm{O}
\end{aligned}
$$

The energy released in this reaction (calculated without phosphorylation of ADP) is- $89 \mathrm{~kJ} / \mathrm{mol} 2,3$-butanediol. The same is true for oxidation of methanol (equation 15) or ethanol (equation 16).

$$
\begin{aligned}
4 \text { methanol }+2 \mathrm{CO}_{2}+ & 2.5 \mathrm{ADP}+2.5 \mathrm{P}_{\mathrm{i}} \rightarrow 3 \text { acetate } \\
& +2 \mathrm{H}_{2} \mathrm{O}+2.5 \mathrm{ATP}
\end{aligned}
$$

$$
2 \text { ethanol }+2 \mathrm{CO}_{2} \rightarrow 3 \text { acetate }
$$

The strategies described so far all apply to pure cultures of acetogens. A fundamentally different strategy is to use consortia of different organisms (Stams, 1994; Stams and Plugge, 2009; Morris et al., 2013; Kouzuma et al., 2015; Angenent et al., 2016). The main products of acetogens such as acetate and ethanol are the substrates for chain elongation via reverse $\beta$ oxidation (Grootscholten et al., 2013; Angenent et al., 2016). Through a combination of syngas fermentation and chain elongation, $\mathrm{C}_{4}, \mathrm{C}_{6}$ and $\mathrm{C}_{8}$ products have been obtained by mixed cultures in open culture fermentation (Angenent et al., 2016). Alternatively, the products of $\mathrm{H}_{2}+\mathrm{CO}_{2}$ or syngas fermentation, ethanol and/or acetate, can be fed to pure cultures of anaerobes such Clostridium kluyveri (Barker and Taha, 1942) to produce n-caproic acid (Barker and Taha, 1942; Gildemyn et al., 2017) or to aerobes such as yeasts (Kerbs et al., 1952; Okada et al., 1981) or Acinetobacter baylyi (Salcedo-Vite et al., 2019). Using this approach, the entire tool box is available for the production of higher value compounds.

\section{REFERENCES}

Abken, H. J., Tietze, M., Brodersen, J., Baumer, S., Beifuss, U., and Deppenmeier, U. (1998). Isolation and characterization of methanophenazine and function of phenazines in membrane-bound electron transport of Methanosarcina mazei Gö1. J. Bacteriol. 180, 2027-2032. doi: 10.1128/JB.180.8.2027-20 32.1998

Abrini, J., Naveau, H., and Nyns, E. J. (1994). Clostridium autoethanogenum, sp. nov., an anaerobic bacterium that produces ethanol from carbon monoxide. Arch. Microbiol. 161, 345-351. doi: 10.1007/BF00303591

Abubackar, H. N., Veiga, M. C., and Kennes, C. (2015). Carbon monoxide fermentation to ethanol by Clostridium autoethanogenum in a bioreactor

\section{CONLCUDING REMARKS}

In times of global climate change alternatives must be explored for a future-proof (bio)technology and energy industry. Renewable energy sources must be used in processes that do not emit $\mathrm{CO}_{2}$ or, even better, capture $\mathrm{CO}_{2}$ and convert it into valuable compounds that are otherwise made petrochemically. In addition, a future-proof energy industry must take into account molecular $\mathrm{H}_{2}$ as promising energy carrier. Different biological solutions are available that solve the most urgent future problems of humanity and are currently tested. Among those are the acetogenic bacteria with their outstanding options to solve these problems. They are the most efficient biocatalysts for $\mathrm{H}_{2}$ storage around and their activity is orders of magnitude higher than any chemical catalyst. They are already used on an industrial scale to convert syngas into ethanol and many more products are currently under investigation. They can not only use $\mathrm{C}_{1}$ gases but also methanol, other primary and secondary alcohols, carbonic acids as well as sugars as driving force for $\mathrm{CO}_{2}$ reduction and there is no other group of anaerobes that has nearly the same metabolic flexibility for $\mathrm{CO}_{2}$ reduction than acetogens. The construction of new acetogenic bioplatforms is still in its infancy but steadily increasing; the genetic tool box required is also steadily increasing. Acetogens have a $\mathrm{CO}_{2}$ fixation pathway that is energy neutral and does not need additional ATP when acetate is the product. Other products that originate from acetylCoA require net input of ATP and, therefore, the main obstacle to overcome in acetogenic fermentations is the energy barrier. This review summarized current knowledge on the strategies to increase the energy charge of the bacteria, some of which have been tested; others could be tested in the future. The road is paved for acetogens to become the key players to achieve a better and more sustainable future for all.

\section{AUTHOR CONTRIBUTIONS}

VM conceived and designed the review article. AK and VM wrote the manuscript and designed the figures.

\section{FUNDING}

This work was funded by financial support of the Federal Ministry for Education and Research (BMBF) for the OBAC project (ERA-IB-16-018). with no accumulation of acetic acid. Bioresour. Technol. 186, 122-127. doi: 10.1016/j.biortech.2015.02.113

Ajanovic, A. (2011). Biofuels versus food production: does biofuels production increase food prices? Energy 36, 2070-2076. doi: 10.1016/j.energy.2010. 05.019

Al-Shorgani, N. K. N., Kalil, M. S., Yusoff, W. M. W., and Hamid, A. A. (2018). Impact of $\mathrm{pH}$ and butyric acid on butanol production during batch fermentation using a new local isolate of Clostridium acetobutylicum YM1. Saudi. J. Biol. Sci. 25, 339-348. doi: 10.1016/j.sjbs.2017.03.020

Andreesen, J. R., Schaupp, A., Neurauter, C., Brown, A., and Ljungdahl, L. G. (1973). Fermentation of glucose, fructose and xylose by Clostridium thermoaceticum: effect of metals on growth yield, enzymes 
and the synthesis of acetate from $\mathrm{CO}_{2}$. J. Bacteriol. 114, 743-751. doi: 10.1128/JB.114.2.743-751.1973

Angenent, L. T., Richter, H., Buckel, W., Spirito, C. M., Steinbusch, K. J., Plugge, C. M., et al. (2016). Chain elongation with reactor microbiomes: open-culture biotechnology to produce biochemicals. Environ. Sci. Technol. 50, 2796-2810. doi: 10.1021/acs.est.5b04847

Anwar, M. N., Fayyaz, A., Sohail, N. F., Khokhar, M. F., Baqar, M., Khan, W. D., et al. (2018). $\mathrm{CO}_{2}$ capture and storage: a way forward for sustainable environment. J. Environ. Manage. 226, 131-144. doi: 10.1016/j.jenvman.2018.08.009

Arendsen, A. F., Soliman, M. Q., and Ragsdale, S. W. (1999). Nitratedependent regulation of acetate biosynthesis and nitrate respiration by Clostridium thermoaceticum. J. Bacteriol. 181, 1489-1495. doi: 10.1128/JB.181.5.1489-1495.1999

Bache, R., and Pfennig, N. (1981). Selective isolation of Acetobacterium woodii on methoxylated aromatic acids and determination of growth yields. Arch. Microbiol. 130, 255-261. doi: 10.1007/BF00459530

Bailera, M. L., Lisbona, P., Romeo, L. M., and Espatolero, S. (2017). Power to gas projects review: lab, pilot and demo plants for storing renewable energy and $\mathrm{CO}_{2}$. Renew. Sustain. Energy. Rev. 69, 292-312. doi: 10.1016/j.rser.2016.11.130

Bajracharya, S., ter Heijne, A., Benetton, X. D., Vanbroekhoven, K., Buisman, C. J., Strik, D. P. B. T.B., et al. (2015). Carbon dioxide reduction by mixed and pure cultures in microbial electrosynthesis using an assembly of graphite felt and stainless steel as a cathode. Bioresour. Technol. 195, 14-24. doi: 10.1016/j.biortech.2015.05.081

Banis, R. J., Roberts, C. S., Stokes, G. B., and Tove, S. B. (1976). Procedure for enzymatic synthesis and isolation of radioactive long chain acyl-CoA esters. Anal. Biochem. 73, 1-8. doi: 10.1016/0003-2697(76)90135-4

Barker, H. A., and Taha, S. M. (1942). Clostridium kluyverii, an organism concerned in the formation of caproic acid from ethyl alcohol. J. Bacteriol. 43, 347-363. doi: 10.1128/JB.43.3.347-363.1942

Basen, M., Schut, G. J., Nguyen, D. M., Lipscomb, G. L., Benn, R. A., Prybol, C. J., et al. (2014). Single gene insertion drives bioalcohol production by a thermophilic archaeon. Proc. Natl. Acad. Sci. U.S.A. 111, 17618-17623. doi: 10.1073/pnas.1413789111

Bäumer, S., Murakami, E., Brodersen, J., Gottschalk, G., Ragsdale, S. W., and Deppenmeier, U. (1998). The $\mathrm{F}_{420} \mathrm{H}_{2}$ :heterodisulfide oxidoreductase system from Methanosarcina species. 2-hydroxyphenazine mediates electron transfer from $\mathrm{F}_{420} \mathrm{H}_{2}$ dehydrogenase to heterodisulfide reductase. FEBS Lett. 428, 295-298. doi: 10.1016/S0014-5793(98)00555-9

Beaty, P. S., and Ljungdahl, L. G. (1990). Thiosulfate reduction by Clostridium thermoaceticum and Clostridium thermoautotrophicum during growth on methanol. Ann. Meet. Am. Soc. Microbiol. 199, 1-7.

Beaty, P. S., and Ljungdahl, L. G. (1991). Growth of Clostridium thermoaceticum on methanol, ethanol or dimethylsulfoxide. Ann. Meet. Am. Soc. Microbiol. $\mathrm{K}, 131-236$.

Beck, M. H., Flaiz, M., Bengelsdorf, F. R., and Dürre, P. (2020). Induced heterologous expression of the arginine deiminase pathway promotes growth advantages in the strict anaerobe Acetobacterium woodii. Appl. Microbiol. Biotechnol. 104, 687-699. doi: 10.1007/s00253-019-10248-9

Bengelsdorf, F. R., Beck, M. H., Erz, C., Hoffmeister, S., Karl, M. M., Riegler, P., et al. (2018). Bacterial anaerobic synthesis gas (syngas) and $\mathrm{CO}_{2}+\mathrm{H}_{2}$ fermentation. Adv. Appl. Microbiol. 103, 143-221. doi: 10.1016/bs.aambs.2018.01.002

Benson, S. M., and Orr, F. M. (2008). Carbon dioxide capture and storage. MRS Bull. 33, 303-305. doi: 10.1557/mrs2008.63

Bertsch, J., and Müller, V. (2015). CO metabolism in the acetogen Acetobacterium woodii. Appl. Environ. Microbiol. 81, 5949-5956. doi: 10.1128/AEM.01772-15

Bertsch, J., Öppinger, C., Hess, V., Langer, J. D., and Müller, V. (2015). A heterotrimeric NADH-oxidizing methylenetetrahydrofolate reductase from the acetogenic bacterium Acetobacterium woodii. J. Bacteriol. 197, 1681-1689. doi: 10.1128/JB.00048-15

Bertsch, J., Siemund, A. L., Kremp, F., and Müller, V. (2016). A novel route for ethanol oxidation in the acetogenic bacterium Acetobacterium woodii: the acetaldehyde/ethanol dehydrogenase pathway. Environ. Microbiol. 18, 2913-2922. doi: 10.1111/1462-2920.13082

Biegel, E., and Müller, V. (2010). Bacterial $\mathrm{Na}^{+}$-translocating ferredoxin:NAD ${ }^{+}$ oxidoreductase. Proc. Natl. Acad. Sci. U.S.A. 107, 18138-18142. doi: $10.1073 /$ pnas. 1010318107
Biegel, E., and Müller, V. (2011). A Na ${ }^{+}$-translocating pyrophosphatase in the acetogenic bacterium Acetobacterium woodii. J. Biol. Chem. 286, 6080-6084. doi: $10.1074 /$ jbc.M110.192823

Biegel, E., Schmidt, S., González, J. M., and Müller, V. (2011). Biochemistry, evolution and physiological function of the Rnf complex, a novel ion-motive electron transport complex in prokaryotes. Cell. Mol. Life Sci. 68, 613-634. doi: 10.1007/s00018-010-0555-8

Blaut, M., and Gottschalk, G. (1984). Protonmotive force-driven synthesis of ATP during methane formation from molecular hydrogen and formaldehyde or carbon dioxide in Methanosarcina barkeri. FEMS Microbiol. Lett. 24, 103-107. doi: 10.1111/j.1574-6968.1984.tb01253.x

Brandt, K., and Müller, V. (2015). Hybrid rotors in $\mathrm{F}_{1} \mathrm{~F}_{(\mathrm{o})}$ ATP synthases: subunit composition, distribution, and physiological significance. Biol. Chem. 396, 1031-1042. doi: 10.1515/hsz-2015-0137

Braun, K., and Gottschalk, G. (1981). Effect of molecular hydrogen and carbon dioxide on chemo-organotrophic growth of Acetobacterium woodii and Clostridium aceticum. Arch. Microbiol. 128, 294-298. doi: 10.1007/BF00422533

Buckel, W., and Thauer, R. K. (2018a). Flavin-based electron bifurcation, a new mechanism of biological energy coupling. Chem. Rev. 118, 3862-3886. doi: 10.1021/acs.chemrev.7b00707

Buckel, W., and Thauer, R. K. (2018b). Flavin-based electron bifurcation, ferredoxin, flavodoxin, and anaerobic respiration with protons (Ech) or NAD ${ }^{+}$ (Rnf) as electron acceptors: a historical review. Front. Microbiol. 9:401. doi: $10.3389 /$ fmicb.2018.00401

Chan, M. K., Mukund, S., Kletzin, A., Adams, M. W. W., and Rees, D. C. (1995). Structure of a hyperthermophilic tungstopterin enzyme, aldehyde ferredoxin oxidoreductase. Science 267, 1463-1469. doi: 10.1126/science.7878465

Cheng, C., Li, W., Lin, M., and Yang, S. T. (2019). Metabolic engineering of Clostridium carboxidivorans for enhanced ethanol and butanol production from syngas and glucose. Bioresour. Technol. 284, 415-423. doi: 10.1016/j.biortech.2019.03.145

Claassen, P. A. M., van Lier, J. B., Lopez Contreras, A. M., van Niel, E. W. J., Sijtsma, L., Stams, A. J. M., et al. (1999). Utilisation of biomass for the supply of energy carriers. Appl. Microbiol. Biotechnol. 52, 741-755. doi: 10.1007/s0025300 51586

Clark, J. E., and Ljungdahl, L. G. (1982). Purification and properties of 5,10methenyltetrahydrofolate cyclohydrolase from Clostridium formicoaceticum. J. Biol. Chem. 257, 3833-3836.

Clark, J. E., and Ljungdahl, L. G. (1984). Purification and properties of 5,10-methylenetetrahydrofolate reductase, an iron-sulfur flavoprotein from Clostridium formicoaceticum. J. Biol. Chem. 259, 10845-10849.

Cotton, C. A., Claassens, N. J., Benito-Vaquerizo, S., and Bar-Even, A. (2019). Renewable methanol and formate as microbial feedstocks. Curr. Opin. Biotechnol. 62, 168-180. doi: 10.1016/j.copbio.2019.10.002

Dalby, P. A. (2011). Strategy and success for the directed evolution of enzymes. Curr. Opin. Struct. Biol. 21, 473-480. doi: 10.1016/j.sbi.2011.05.003

Daniell, J., Köpke, M., and Simpson, S. D. (2012). Commercial biomass syngas fermentation. Energies 5, 5372-5417. doi: 10.3390/en5125372

Das, A., Hugenholtz, J., Van Halbeek, H., and Ljungdahl, L. G. (1989). Structure and function of a menaquinone involved in electron transport in membranes of Clostridium thermoautotrophicum and Clostridium thermoaceticum. J. Bacteriol. 171, 5823-5829. doi: 10.1128/JB.171.11.5823-5829.1989

Das, A., Ivey, D. M., and Ljungdahl, L. G. (1997). Purification and reconstitution into proteoliposomes of the $\mathrm{F}_{1} \mathrm{~F}_{0}$ ATP synthase from the obligately anaerobic gram-positive bacterium Clostridium thermoautotrophicum. J. Bacteriol. 179, 1714-1720. doi: 10.1128/JB.179.5.1714-1720.1997

Das, A., and Ljungdahl, L. G. (2003). "Electron-transport systems in acetogens," in Biochemistry and Physiology of Anaerobic Bacteria, eds. L.G. Ljungdahl, M.W. Adams, L.L. Barton, J.G. Ferry and M.K. Johnson (New York, NY: Springer), 191-204. doi: 10.1007/0-387-22731-8_14

Deibel, R. H. (1964). Utilization of arginine as an energy source for the growth of Streptococcus faecalis. J. Bacteriol. 87, 988-992. doi: 10.1128/JB.87.5.988-992.1964

Deppenmeier, U. (2002). The unique biochemistry of methanogenesis. Prog. Nucleic. Acid. Res. Mol. Biol. 71, 223-283. doi: 10.1016/S0079-6603(02)71045-3

Dey, G. R. (2007). Chemical reduction of $\mathrm{CO}_{2}$ to different products during photo catalytic reaction on $\mathrm{TiO}_{2}$ under diverse conditions: an overview. J. Nat. Gas Chem. 16, 217-226. doi: 10.1016/S1003-9953(07)60052-8 
Diekert, G., Schrader, E., and Harder, W. (1986). Energetics of CO formation and $\mathrm{CO}$ oxidation in cell suspensions of Acetobacterium woodii. Arch. Microbiol. 144, 386-392. doi: 10.1007/BF00409889

Dilling, S., Imkamp, F., Schmidt, S., and Müller, V. (2007). Regulation of caffeate respiration in the acetogenic bacterium Acetobacterium woodii. Appl. Environ. Microbiol. 73, 3630-3636. doi: 10.1128/AEM.02060-06

Dimroth, P., and Thomer, A. (1986). Citrate transport in Klebsiella pneumoniae. Biol. Chem. Hoppe Seyler 367, 813-823. doi: 10.1515/bchm3.1986.367.2.813

Diner, B. A., Fan, J., Scotcher, M. C., Wells, D. H., and Whited, G. M. (2018). Synthesis of heterologous mevalonic acid pathway enzymes in Clostridium ljungdahlii for the conversion of fructose and of syngas to mevalonate and isoprene. Appl. Environ. Microbiol. 84, e01723-e01717. doi: 10.1128/AEM.01723-17

Dorn, M., Andreesen, J. R., and Gottschalk, G. (1978). Fermentation of fumarate and L-malate by Clostridium formicoaceticum. J. Bacteriol. 133, 26-32. doi: 10.1128/JB.133.1.26-32.1978

Drake, H. L., Daniel, S., Küsel, K., Matthies, C., Kuhner, C., and Braus-Strohmeyer, S. (1997). Acetogenic bacteria: what are the in situ consequences of their diverse metabolic diversities? Biofactors 1, 13-24. doi: 10.1002/biof.5520060103

Drake, H. L., Gößner, A. S., and Daniel, S. L. (2008). Old acetogens, new light. Ann. N. Y. Acad. Sci. 1125, 100-128. doi: 10.1196/annals.1419.016

Drake, H. L., Hu, S. I., and Wood, H. G. (1980). Purification of carbon monoxide dehydrogenase, a nickel enzyme from Clostridium thermocaceticum. J. Biol. Chem. 255, 7174-7180.

Drake, H. L., Hu, S. I., and Wood, H. G. (1981). Purification of five components from Clostridium thermoaceticum which catalyze synthesis of acetate from pyruvate and methyltetrahydrofolate. J. Biol. Chem. 56, 11137-11144.

Dürre, P. (2007). Biobutanol: an attractive biofuel. Biotechnol. J. 2, 1525-1534. doi: 10.1002/biot.200700168

Dürre, P. (2017). Gas fermentation - a biotechnological solution for today's challenges. Microb. Biotechnol. 10, 14-16. doi: 10.1111/1751-7915.12431

Dürre, P., Bahl, H., and Gottschalk, G. (1992). Acetone-butanol fermentation basis of a modern biotechnological process. Chem. Ing. Tech. 64, 491-498. doi: $10.1002 /$ cite. 330640603

Eichler, B., and Schink, B. (1984). Oxidation of primary aliphatic alcohols by Acetobacterium carbinolicum sp. nov., a homoacetogenic anaerobe. Arch. Microbiol. 140, 147-152. doi: 10.1007/BF00454917

Eichler, B., and Schink, B. (1985). Fermentation of primary alcohols and diols and pure culture of syntrophically alcohol-oxidizing anaerobes. Arch. Microbiol. 143, 60-66. doi: 10.1007/BF00414769

Emerson, D. F., Woolston, B. M., Liu, N., Donnelly, M., Currie, D. H., and Stephanopoulos, G. (2019). Enhancing hydrogen-dependent growth of and carbon dioxide fixation by Clostridium ljungdahlii through nitrate supplementation. Biotechnol. Bioeng. 116, 294-306. doi: 10.1002/bit. 26847

Enzmann, F., Mayer, F., Rother, M., and Holtmann, D. (2018). Methanogens: biochemical background and biotechnological applications. AMB Expr. 8:1. doi: 10.1186/s13568-017-0531-x

Extance, J., Crennell, S. J., Eley, K., Cripps, R., Hough, D. W., and Danson, M. J. (2013). Structure of a bifunctional alcohol dehydrogenase involved in bioethanol generation in Geobacillus thermoglucosidasius. Acta. Crystallogr. D. Biol. Crystallogr. 69, 2104-2115. doi: 10.1107/S09074449130 20349

Ferguson, S. A., Keis, S., and Cook, G. M. (2006). Biochemical and molecular characterization of a $\mathrm{Na}^{+}$-translocating $\mathrm{F}_{1} \mathrm{~F}_{\mathrm{O}}$-ATPase from the thermoalkaliphilic bacterium Clostridium paradoxum. J. Bacteriol. 188, 5045-5054. doi: 10.1128/JB.00128-06

Fillingame, R. H., Angevine, C. M., and Dmitriev, O. Y. (2003). Mechanics of coupling proton movements to $c$-ring rotation in ATP synthase. FEBS Lett. 555, 29-34. doi: 10.1016/S0014-5793(03)01101-3

Fritz, M., and Müller, V. (2007). An intermediate step in the evolution of ATPases - the $\mathrm{F}_{1} \mathrm{~F}_{\mathrm{O}}$-ATPase from Acetobacterium woodii contains F-type and V-type rotor subunits and is capable of ATP synthesis. FEBS J. 274, 3421-3428. doi: 10.1111/j.1742-4658.2007.05874.x

Fröstl, J. M., Seifritz, C., and Drake, H. L. (1996). Effect of nitrate on the autotrophic metabolism of the acetogens Clostridium thermoautotrophicum and Clostridium thermoaceticum. J. Bacteriol. 178, 4597-4603. doi: 10.1128/JB.178.15.4597-4603.1996
Fuchs, G. (2011). Alternative pathways of carbon dioxide fixation: insights into the early evolution of life? Annu. Rev. Microbiol. 65, 631-658. doi: 10.1146/annurev-micro-090110-10 2801

Furdui, C., and Ragsdale, S. W. (2000). The role of pyruvate ferredoxin oxidoreductase in pyruvate synthesis during autotrophic growth by the Wood-Ljungdahl pathway. J. Biol. Chem. 275, 28494-28499. doi: $10.1074 /$ jbc.M003291200

Gildemyn, S., Molitor, B., Usack, J. G., Nguyen, M., Rabaey, K., and Angenent, L. T. (2017). Upgrading syngas fermentation effluent using Clostridium kluyveri in a continuous fermentation. Biotechnol. Biofuels 10:83. doi: 10.1186/s13068-017-0764-6

Gladden, L. B. (2004). Lactate metabolism: a new paradigm for the third millennium. J. Physiol. 558, 5-30. doi: 10.1113/jphysiol.2003.058701

Goodlove, P. E., Cunningham, P. R., Parker, J., and Clark, D. P. (1989). Cloning and sequence analysis of the fermentative alcohol-dehydrogenase-encoding gene of Escherichia coli. Gene 85, 209-214. doi: 10.1016/0378-1119(89)90483-6

Gottwald, M., Andreesen, J. R., LeGall, J., and Ljungdahl, L. G. (1975). Presence of cytochrome and menaquinone in Clostridium formicoaceticum and Clostridium thermoaceticum. J. Bacteriol. 122, 325-328. doi: 10.1128/JB.122.1.325-328.1975

Götz, M. L., Mörs, J., Koch, F., Graf, A. M., Bajohr, F., Reimert, S., et al. (2016). Renewable power-to-gas: a technological and economic review. Renew. Energy 85, 1371-1390. doi: 10.1016/j.renene.2015.07.066

Grisolia, S., Harmon, P., and Raijman, L. (1962). Studies on the mechanism of action of carbamate kinase. Biochim. Biophys. Acta. 62, 293-299. doi: 10.1016/0006-3002(62)90042-2

Grootscholten, T. I., Steinbusch, K. J., Hamelers, H. V., and Buisman, C. J. (2013). Chain elongation of acetate and ethanol in an upflow anaerobic filter for high rate MCFA production. Bioresour. Technol. 135, 440-445. doi: 10.1016/j.biortech.2012.10.165

Grüber, G., Manimekalai, M. S., Mayer, F., and Müller, V. (2014). ATP synthases from archaea: the beauty of a molecular motor. Biochim. Biophys. Acta. 1837, 940-952. doi: 10.1016/j.bbabio.2014.03.004

Hackmann, T. J., and Firkins, J. L. (2015). Electron transport phosphorylation in rumen butyrivibrios: unprecedented ATP yield for glucose fermentation to butyrate. Front. Microbiol. 6:622. doi: 10.3389/fmicb.2015.00622

Hager, L. B. (1962). "Succinyl CoA synthetase" in The Enzymes, eds. P.D. Boyer, H. Lardy, and K. Myrbäck (New York, NY: Academic Press), 387-399.

Hattori, S., Kamagata, Y., Hanada, S., and Shoun, H. (2000). Thermacetogenium phaeum gen. nov., sp. nov., a strictly anaerobic, thermophilic, syntrophic acetate-oxidizing bacterium. Int. J. Syst. Evol. Microbiol. 50, 1601-1609. doi: 10.1099/00207713-50-4-1601

Hedderich, R., and Forzi, L. (2005). Energy-converting [NiFe] hydrogenases: more than just $\mathrm{H}_{2}$ activation. J. Mol. Microbiol. Biotechnol. 10, 92-104. doi: $10.1159 / 000091557$

Heider, J., Ma, K., and Adams, M. W. (1995). Purification, characterization, and metabolic function of tungsten-containing aldehyde ferredoxin oxidoreductase from the hyperthermophilic and proteolytic archaeon Thermococcus strain ES-1. J. Bacteriol. 177, 4757-4764. doi: 10.1128/JB.177.16.4757-4764.1995

Heijstra, B. D., Leang, C., and Juminaga, A. (2017). Gas fermentation: cellular engineering possibilities and scale up. Microb. Cell Fact. 16:60. doi: 10.1186/s12934-017-0676-y

Hernandez, E., and Johnson, M. J. (1967). Anaerobic growth yields of Aerobacter cloacae and Escherichia coli. J. Bacteriol. 94, 991-995. doi: 10.1128/JB.94.4.991-995.1967

Hess, V., Gonzalez, J. M., Parthasarathy, A., Buckel, W., and Müller, V. (2013a). Caffeate respiration in the acetogenic bacterium Acetobacterium woodii: a coenzyme A loop saves energy for caffeate activation. Appl. Environ. Microbiol. 79, 1942-1947. doi: 10.1128/AEM.03604-12

Hess, V., Oyrik, O., Trifunovic, D., and Müller, V. (2015). 2,3-butanediol metabolism in the acetogen Acetobacterium woodii. Appl. Environ. Microbiol. 81, 4711-4719. doi: 10.1128/AEM.00960-15

Hess, V., Schuchmann, K., and Müller, V. (2013b). The ferredoxin:NAD ${ }^{+}$ oxidoreductase (Rnf) from the acetogen Acetobacterium woodii requires $\mathrm{Na}^{+}$ and is reversibly coupled to the membrane potential. J. Biol. Chem. 288, 31496-31502. doi: 10.1074/jbc.M113.510255

Himes, R. H., and Harmony, J. A. (1973). Formyltetrahydrofolate synthetase. CRC Crit. Rev. Biochem. 1, 501-535. doi: 10.3109/10409237309105441 
Hoffmeister, S., Gerdom, M., Bengelsdorf, F. R., Linder, S., Fluchter, S., Oztürk, H., et al. (2016). Acetone production with metabolically engineered strains of Acetobacterium woodii. Metab. Eng. 36, 37-47. doi: 10.1016/j.ymben.2016.03.001

Hugenholtz, J., and Ljungdahl, L. G. (1989). Electron transport and electrochemical proton gradient in membrane vesicles of Clostridium thermoaceticum. J. Bacteriol. 171, 2873-2875. doi: 10.1128/JB.171.5.2873-2875.1989

Imkamp, F., and Müller, V. (2002). Chemiosmotic energy conservation with $\mathrm{Na}^{+}$as the coupling ion during hydrogen-dependent caffeate reduction by Acetobacterium woodii. J. Bacteriol. 184, 1947-1951. doi: 10.1128/JB.184.7.1947-1951.2002

Ivey, D. M., and Ljungdahl, L. G. (1986). Purification and characterization of the $\mathrm{F}_{1}$-ATPase from Clostridium thermoaceticum. J. Bacteriol. 165, 252-257. doi: 10.1128/JB.165.1.252-257.1986

Kalman, S. M., Duffield, P. H., and Brzozowski, T. (1965). Identity in Escherichia coli of carbamyl phosphokinase and an activity which catalyzes amino group transfer from glutamine to ornithine in citrulline synthesis. Biochem. Biophys. Res. Commun. 18, 530-537. doi: 10.1016/0006-291X(65)90786-2

Kamlage, B., and Blaut, M. (1993). Isolation of a cytochrome-deficient mutant strain of Sporomusa sphaeroides not capable of oxidizing methyl groups. J. Bacteriol. 175, 3043-3050. doi: 10.1128/JB.175.10.3043-3050.1993

Kamlage, B., Boelter, A., and Blaut, M. (1993). Spectroscopic and potentiometric characterization of cytochromes in 2 Sporomusa species and their expression during growth on selected substrates. Arch. Microbiol. 159, 189-196. doi: $10.1007 /$ BF00250281

Keller, A., Schink, B., and Müller, N. (2019). Alternative pathways of acetogenic ethanol and methanol degradation in the thermophilic anaerobe Thermacetogenium phaeum. Front. Microbiol. 10:423. doi: $10.3389 /$ fmicb. 2019.00423

Kerbs, H. A., Gurin, S., and Eggleston, L. V. (1952). The pathway of oxidation of acetate in baker's yeast. Biochem. J. 51, 614-628. doi: 10.1042/bj 0510614

Kim, Y. M., and Hegeman, G. D. (1983). Oxidation of carbon monoxide by bacteria. Int. Rev. Cytol. 81, 1-32. doi: 10.1016/S0074-7696(08)62333-5

Kimmich, G. A., Randles, J., and Bennett, E. (1991). Sodium-dependent succinate transport by isolated chick intestinal cells. Am. J. Physiol. 260, C1151-C1157. doi: 10.1152/ajpcell.1991.260.6.C1151

Klask, C. M., Kliem-Kuster, N., Molitor, B., and Angenent, L. T. (2020). Nitrate feed improves growth and ethanol production of Clostridium ljungdahlii with $\mathrm{CO}_{2}$ and $\mathrm{H}_{2}$, but results in stochastic inhibition events. Front. Microbiol. 11:724. doi: $10.3389 /$ fmicb.2020.00724

Köpke, M., Mihalcea, C., Bromley, J. C., and Simpson, S. D. (2011a). Fermentative production of ethanol from carbon monoxide. Curr. Opin. Biotechnol. 22, 320-325. doi: 10.1016/j.copbio.2011.01.005

Köpke, M., Mihalcea, C., Liew, F., Tizard, J. H., Ali, M. S., Conolly, J. J., et al. (2011b). 2,3-butanediol production by acetogenic bacteria, an alternative route to chemical synthesis, using industrial waste gas. Appl. Environ. Microbiol. 77, 5467-5475. doi: 10.1128/AEM.00355-11

Köpke, M., and Simpson, S. D. (2020). Pollution to products: recycling of 'above ground' carbon by gas fermentation. Curr. Opin. Biotechnol. 65, 180-189. doi: 10.1016/j.copbio.2020.02.017

Köpke, M., Steffi, N., and Dürre, P. (2011c). "The past, present, and future of biofuels-biobutanol as promising alternative," in Biofuel Production Recent Developments and Prospects, ed. D. M. A. D. S. Bernardes (Rijeka: InTech), 451-486.

Kouzuma, A., Kato, S., and Watanabe, K. (2015). Microbial interspecies interactions: recent findings in syntrophic consortia. Front. Microbiol. 6:477. doi: $10.3389 /$ fmicb.2015.00477

Kremp, F., Roth, J., and Müller, V. (2020). The Sporomusa type Nfn is a novel type of electron-bifurcating transhydrogenase that links the redox pools in acetogenic bacteria. Sci. Rep. 10:14872. doi: 10.1038/s41598-020-71038-2

Kühn, W., Fiebig, K., Walther, R., and Gottschalk, G. (1979). Presence of a cytochrome $b_{559}$ in Methanosarcina barkeri. FEBS Lett. 105, 271-274. doi: 10.1016/0014-5793(79)80627-4

Kuhns, M., Trifunović, D., Huber, H., and Müller, V. (2020). The Rnf complex is a $\mathrm{Na}^{+}$coupled respiratory enzyme in a fermenting bacterium, Thermotoga maritima. Commun. Biol. 3:431. doi: 10.1038/s42003-020-01158-y
Kumagai, H., Fujiwara, T., Matsubara, H., and Saeki, K. (1997). Membrane localization, topology, and mutual stabilization of the $\operatorname{rnf} A B C$ gene products in Rhodobacter capsulatus and implications for a new family of energy-coupling NADH oxidoreductases. Biochemistry 36, 5509-5521. doi: 10.1021/bi970014q

Kuzuyama, T. (2002). Mevalonate and nonmevalonate pathways for the biosynthesis of isoprene units. Biosci. Biotechnol. Biochem. 66, 1619-1627. doi: $10.1271 / \mathrm{bbb} .66 .1619$

Lancaster, J. R. (1989). Sodium, protons, and energy coupling in the methanogenic bacteria. J. Bioenerg. Biomembr. 21, 717-740. doi: 10.1007/BF00762689

Leung, D. L. C., Caramanna, G., and Maroto-Valer, M. M. (2014). An overview of current status of carbon dioxide capture and storage technologies. Renew. Sustain. Energy Rev. 39, 426-443. doi: 10.1016/j.rser.2014.07.093

Li, F., Hinderberger, J., Seedorf, H., Zhang, J., Buckel, W., and Thauer, R. K. (2008). Coupled ferredoxin and crotonyl coenzyme A $(\mathrm{CoA})$ reduction with $\mathrm{NADH}$ catalyzed by the butyryl-CoA dehydrogenase/Etf complex from Clostridium kluyveri. J. Bacteriol. 190, 843-850. doi: 10.1128/JB.01417-07

Liew, F., Henstra, A. M., Köpke, M., Winzer, K., Simpson, S. D., and Minton, N. P. (2017). Metabolic engineering of Clostridium autoethanogenum for selective alcohol production. Metab. Eng. 40, 104-114. doi: 10.1016/j.ymben.2017.01.007

Liew, F., Martin, M. E., Tappel, R. C., Heijstra, B. D., Mihalcea, C., and Köpke, M. (2016). Gas fermentation - a flexible platform for commercial scale production of low-carbon-fuels and chemicals from waste and renewable feedstocks. Front. Microbiol. 7:694. doi: 10.3389/fmicb.2016.00694

Litty, D., and Müller, V. (2020). A Na ${ }^{+} \mathrm{A}_{1} \mathrm{~A}_{\mathrm{O}} \mathrm{ATP}$ synthase with a V-type $c$ subunit in a mesophilic bacterium. FEBS J. 287, 3012-3023. doi: 10.1111/febs.15193

Liu, S., and Suflita, J. M. (1995). $\mathrm{H}_{2}$ as an energy source for mixotrophic acetogenesis from the reduction of $\mathrm{CO}_{2}$ and syringate by Acetobacterium woodii and Eubacterium limosum. Curr. Microbiol. 31, 245-250. doi: $10.1007 / \mathrm{BF} 00298382$

Ljungdahl, L. G. (1986). The autotrophic pathway of acetate synthesis in acetogenic bacteria. Ann. Rev. Microbiol. 40, 415-450. doi: 10.1146/annurev.mi.40.100186.002215

Lo, J., Zheng, T., Hon, S., Olson, D. G., and Lynd, L. R. (2015). The bifunctional alcohol and aldehyde dehydrogenase gene, $a d h E$, is necessary for ethanol production in Clostridium thermocellum and Thermoanaerobacterium saccharolyticum. J. Bacteriol. 197, 1386-1393. doi: 10.1128/JB.02450-14

Lovell, C. R., Przybyla, A., and Ljungdahl, L. G. (1988). Cloning and expression in Escherichia coli of the Clostridium thermoaceticum gene encoding thermostable formyltetrahydrofolate synthetase. Arch. Microbiol. 149, 280-285. doi: 10.1007/BF00411642

Martin, M. E., Richter, H., Saha, S., and Angenent, L. T. (2016). Traits of selected Clostridium strains for syngas fermentation to ethanol. Biotechnol. Bioeng. 113, 531-539. doi: 10.1002/bit.25827

Matthies, C., Freiberger, A., and Drake, H. L. (1993). Fumarate dissimilation and differential reductant flow by Clostridium formicoaceticum and Clostridium aceticum. Arch. Microbiol. 160, 273-278. doi: 10.1007/BF00292076

Matthies, D., Zhou, W., Klyszejko, A. L., Anselmi, C., Yildiz, O., Brandt, K., et al. (2014). High-resolution structure and mechanism of an F/Vhybrid rotor ring in a $\mathrm{Na}^{+}$-coupled ATP synthase. Nat. Commun. 5:5286. doi: $10.1038 /$ ncomms 6286

Mayer, F., Ivey, D. M., and Ljungdahl, L. G. (1986). Macromolecular organization of $\mathrm{F}_{1}$-ATPase isolated from Clostridium thermoaceticum as revealed by electron microscopy. J. Bacteriol. 166, 1128-1130. doi: 10.1128/JB.166.3.1128-1130.1986

Mayer, F., Lim, J. K., Langer, J. D., Kang, S. G., and Müller, V. (2015). $\mathrm{Na}^{+}$transport by the $\mathrm{A}_{1} \mathrm{~A}_{\mathrm{O}}$-ATP synthase purified from Thermococcus onnurineus and reconstituted into liposomes. J. Biol. Chem. 290, 6994-7002. doi: 10.1074/jbc.M114.616862

Meier, T., Ferguson, S. A., Cook, G. M., Dimroth, P., and Vonck, J. (2006). Structural investigations of the membrane-embedded rotor ring of the F-ATPase from Clostridium paradoxum. J. Bacteriol. 188, 7759-7764. doi: $10.1128 /$ B. $00934-06$

Meier, T., Krah, A., Bond, P. J., Pogoryelov, D., Diederichs, K., and FaraldoGómez, J. D. (2009). Complete ion-coordination structure in the rotor ring of $\mathrm{Na}^{+}$-dependent F-ATP synthases. J. Mol. Biol. 391, 498-507. doi: 10.1016/j.jmb.2009.05.082

Meier, T., Polzer, P., Diederichs, K., Welte, W., and Dimroth, P. (2005). Structure of the rotor ring of F-type $\mathrm{Na}^{+}$-ATPase from Ilyobacter tartaricus. Science 308, 659-662. doi: 10.1126/science.1111199 
Meuer, J., Kuettner, H. C., Zhang, J. K., Hedderich, R., and Metcalf, W. W. (2002). Genetic analysis of the archaeon Methanosarcina barkeri fusaro reveals a central role for Ech hydrogenase and ferredoxin in methanogenesis and carbon fixation. Proc. Natl. Acad. Sci. U.S.A. 99, 5632-5637. doi: 10.1073/pnas.072615499

Misoph, M., Daniel, S. L., and Drake, H. L. (1996). Bidirectional usage of ferulate by the acetogen Peptostreptococcus productus U-1: $\mathrm{CO}_{2}$ and aromatic acrylate groups as competing electron acceptors. Microbiology 142, 1983-1988. doi: 10.1099/13500872-142-8-1983

Misoph, M., and Drake, H. L. (1996). Effect of $\mathrm{CO}_{2}$ on the fermentation capacities of the acetogen Peptostreptococcus productus U-1. J. Bacteriol. 178, 3140-3145. doi: 10.1128/JB.178.11.3140-3145.1996

Mock, J., Wang, S., Huang, H., Kahnt, J., and Thauer, R. K. (2014). Evidence for a hexaheteromeric methylenetetrahydrofolate reductase in Moorella thermoacetica. J. Bacteriol. 196, 3303-3314. doi: 10.1128/JB.01 839-14

Mock, J., Zheng, Y., Müller, A. P., Ly, S., Tran, L., Segovia, S., et al. (2015). Energy conservation associated with ethanol formation from $\mathrm{H}_{2}$ and $\mathrm{CO}_{2}$ in Clostridium autoethanogenum involving electron bifurcation. J. Bacteriol. 197, 2965-2980. doi: 10.1128/JB.00399-15

Moon, J., Jain, S., Müller, V., and Basen, M. (2020). Homoacetogenic conversion of mannitol by the thermophilic acetogenic bacterium Thermoanaerobacter kivui requires external $\mathrm{CO}_{2}$. Front. Microbiol. 11:571736. doi: $10.3389 /$ fmicb. 2020.571736

Moore, M. R., O’Brien, W. E., and Ljungdahl, L. G. (1974). Purification and characterization of nicotinamide adenine dinucleotide-dependent methylenetetrahydrofolate dehydrogenase from Clostridium formicoaceticum. J. Biol. Chem. 249, 5250-5253.

Morris, B. E., Henneberger, R., Huber, H., and Moissl-Eichinger, C. (2013). Microbial syntrophy: interaction for the common good. FEMS Microbiol. Rev. 37, 384-406. doi: 10.1111/1574-6976.12019

Müller, V. (2003). Energy conservation in acetogenic bacteria. Appl. Environ. Microbiol. 69, 6345-6353. doi: 10.1128/AEM.69.11.6345-6353.2003

Müller, V. (2008). "Bacterial Fermentation" in Encyclopedia of Life Sciences. (Chichester: John Wiley \& Sons Ltd).

Müller, V. (2014). Bioalcohol production by a new synthetic route in a hyperthermophilic archaeon. Proc. Natl. Acad. Sci. U.S.A. 111, 17352-17353. doi: 10.1073/pnas.1420385111

Müller, V. (2019). New horizons in acetogenic conversion of one-carbon substrates and biological hydrogen storage. Trends Biotechnol. 37, 1344-1354. doi: 10.1016/j.tibtech.2019.05.008

Müller, V., Chowdhury, N. P., and Basen, M. (2018). Electron bifurcation: a long-hidden energy-coupling mechanism. Annu. Rev. Microbiol. 72, 331-353. doi: 10.1146/annurev-micro-090816-093440

Müller, V., and Grüber, G. (2003). ATP synthases: structure, function and evolution of unique energy converters. Cell. Mol. Life Sci. 60, 474-494. doi: $10.1007 / \mathrm{s} 000180300040$

Müller, V., Imkamp, F., Biegel, E., Schmidt, S., and Dilling, S. (2008). Discovery of a ferredoxin: $\mathrm{NAD}^{+}$-oxidoreductase (Rnf) in Acetobacterium woodii: a novel potential coupling site in acetogens. Ann. N. Y. Acad. Sci. 1125, 137-146. doi: 10.1196/annals.1419.011

Müller, V., Inkamp, F., Rauwolf, A., Küsel, K., and Drake, H. L. (2004). “Molecular and cellular biology of acetogenic bacteria," in Strict and Facultative Anaerobes: Medical and Environmental Aspects, eds. M. Nakano and P. Zuber (Norfolk: Horizon Scientific Press), 251-281.

Nagarajan, H., Sahin, M., Nogales, J., Latif, H., Lovley, D. R., Ebrahim, A., et al. (2013). Characterizing acetogenic metabolism using a genome-scale metabolic reconstruction of Clostridium ljungdahlii. Microb. Cell Fact. 12:118. doi: 10.1186/1475-2859-12-118

Naik, S. N., Goud, V. V., Rout, P. K., and Dalai, A. K. (2010). Production of first and second generation biofuels: a comprehensive review. Renew. Sust. Energ. Rev. 14, 578-597. doi: 10.1016/j.rser.2009. 10.003

Nguyen, D. M. N., Schut, G. J., Zadvornyy, O. A., Tokmina-Lukaszewska, M., Poudel, S., Lipscomb, G. L., et al. (2017). Two functionally distinct $\mathrm{NADP}^{+}$-dependent ferredoxin oxidoreductases maintain the primary redox balance of Pyrococcus furiosus. J. Biol. Chem. 292, 14603-14616. doi: $10.1074 /$ jbc.M117.794172
Ni, Y., Hagedoorn, P. L., Xu, J. H., Arends, I. W., and Hollmann, F. (2012). A biocatalytic hydrogenation of carboxylic acids. Chem. Commun. 48, 12056-12058. doi: 10.1039/c2cc36479d

Nissen, L. S., and Basen, M. (2019). The emerging role of aldehyde:ferredoxin oxidoreductases in microbially-catalyzed alcohol production. J. Biotechnol. 306, 105-117. doi: 10.1016/j.jbiotec.2019.09.005

Novak, L., Zubacova, Z., Karnkowska, A., Kolisko, M., Hroudova, M., Stairs, C. W., et al. (2016). Arginine deiminase pathway enzymes: evolutionary history in metamonads and other eukaryotes. BMC Evol. Biol. 16:197. doi: 10.1186/s12862-016-0771-4

Novelli, P. C., Lang, P. M., Masarie, K. A., Hurst, D. F., Myers, R., and Elkins, J. W. (1999). Molecular hydrogen in the troposphere: global distribution and budget. J. Geophys. Res. 104, 30427-30444. doi: 10.1029/1999JD900788

O'Brien, W. E., Brewer, J. M., and Ljungdahl, L. G. (1973). Purification and characterization of thermostable 5,10-methylenetetrahydrofolate dehydrogenase from Clostridium thermoaceticum. J. Biol. Chem. 248, 403-408.

Okada, W., Fukuda, H., and Morikawa, H. (1981). Kinetic expressions of ethanol production rate and ethanol consumption rate in baker's yeast cultivation. $J$. Ferment. Technol. 59, 103-109.

Parke, D., and Ornston, L. N. (2004). Toxicity caused by hydroxycinnamoylcoenzyme A thioester accumulation in mutants of Acinetobacter sp. strain ADP1. Appl. Environ. Microbiol. 70, 2974-2983. doi: 10.1128/AEM.70.5.2974-2983.2004

Peng, H., Wu, G., and Shao, W. (2008). The aldehyde/alcohol dehydrogenase (AdhE) in relation to the ethanol formation in Thermoanaerobacter ethanolicus JW200. Anaerobe 14, 125-127. doi: 10.1016/j.anaerobe.2007.09.004

Perez, J. M., Richter, H., Loftus, S. E., and Angenent, L. T. (2013). Biocatalytic reduction of short-chain carboxylic acids into their corresponding alcohols with syngas fermentation. Biotechnol. Bioeng. 110, 1066-1077. doi: 10.1002/bit.24786

Petrack, B., Sullivan, L., and Ratner, S. (1957). Behavior of purified arginine desiminase from S. faecalis. Arch. Biochem. Biophys. 69, 186-197. doi: 10.1016/0003-9861(57)90485-X

Pezacka, E., and Wood, H. G. (1984). The synthesis of acetyl-CoA by Clostridium thermoaceticum from carbon dioxide, hydrogen, coenzyme A and methyltetrahydrofolate. Arch. Microbiol. 137, 63-69. doi: 10.1007/BF00425809

Philips, J. (2020). Extracellular electron uptake by acetogenic bacteria: does $\mathrm{H}_{2}$ consumption favor the $\mathrm{H}_{2}$ evolution reaction on a cathode or metallic iron? Front. Microbiol. 10:2997. doi: 10.3389/fmicb.2019.02997

Pierce, E., Xie, G., Barabote, R. D., Saunders, E., Han, C. S., Detter, J. C., et al. (2008). The complete genome sequence of Moorella thermoacetica (f. Clostridium thermoaceticum). Environ. Microbiol. 10, 2550-2573. doi: 10.1111/j.1462-2920.2008.01679.x

Poehlein, A., Cebulla, M., Ilg, M. M., Bengelsdorf, F. R., Schiel-Bengelsdorf, B., Whited, G., et al. (2015). The complete genome sequence of Clostridium aceticum: a missing link between Rnf- and cytochrome-containing autotrophic acetogens. Mbio 6, e01168-e01115. doi: 10.1128/mBio.0 $1168-15$

Poehlein, A., Gottschalk, G., and Daniel, R. (2013). First insights into the genome of the gram-negative, endospore-forming organism Sporomusa ovata strain H1 DSM 2662. Genome Announc. 1, e00734-e00713. doi: 10.1128/genomeA.00734-13

Poehlein, A., Schmidt, S., Kaster, A.-K., Goenrich, M., Vollmers, J., Thürmer, A., et al. (2012). An ancient pathway combining carbon dioxide fixation with the generation and utilization of a sodium ion gradient for ATP synthesis. PLoS ONE 7:e33439. doi: 10.1371/journal.pone.0033439

Ragsdale, S. W., and Ljungdahl, L. G. (1984). Purification and properties of NAD-dependent 5,10-methylenetetrahydrofolate dehydrogenase from Acetobacterium woodii. J. Biol. Chem. 259, 3499-3503.

Ragsdale, S. W., and Pierce, E. (2008). Acetogenesis and the Wood-Ljungdahl pathway of $\mathrm{CO}_{2}$ fixation. Biochim. Biophys. Acta 1784, 1873-1898. doi: 10.1016/j.bbapap.2008.08.012

Ragsdale, S. W., and Wood, H. G. (1985). Acetate biosynthesis by acetogenic bacteria. Evidence that carbon monoxide dehydrogenase is the condensing enzyme that catalyzes the final steps in the synthesis. J. Biol. Chem. 260, 3970-3977.

Rahlfs, S., and Müller, V. (1999). Sequence of subunit a of the $\mathrm{Na}^{+}$. translocating $\mathrm{F}_{1} \mathrm{~F}_{\mathrm{O}}$-ATPase of Acetobacterium woodii: proposal for residues 
involved in $\mathrm{Na}^{+}$binding. FEBS Lett. 453, 35-40. doi: 10.1016/S0014-5793(99)0 0576-1

Raybuck, S. A., Bastian, N. R., Orme-Johnson, W. H., and Walsh, C. T. (1988). Kinetic characterization of the carbon monoxide-acetyl-CoA (carbonyl group) exchange activity of the acetyl-CoA synthesizing CO dehydrogenase from Clostridium thermoaceticum. Biochemistry 27, 7698-7702. doi: 10.1021/bi00420a019

Reidlinger, J., Mayer, F., and Müller, V. (1994). The molecular structure of the $\mathrm{Na}^{+}$translocating $\mathrm{F}_{1} \mathrm{~F}_{\mathrm{O}}$-ATPase of Acetobacterium woodii, as revealed by electron microscopy, resembles that of $\mathrm{H}^{+}$-translocating ATPases. FEBS Lett. 356, 17-20. doi: 10.1016/0014-5793(94)01222-9

Reidlinger, J., and Müller, V. (1994). Purification of ATP synthase from Acetobacterium woodii and identification as a $\mathrm{Na}^{+}$translocating $\mathrm{F}_{1} \mathrm{~F}_{\mathrm{O}}$-type enzyme. Eur. J. Biochem. 223, 275-283. doi: 10.1111/j.1432-1033.1994.tb18992.x

Richter, H., Molitor, B., Diender, M., Sousa, D. Z., and Angenent, L. T. (2016a), A narrow $\mathrm{pH}$ range supports butanol, hexanol, and octanol production from syngas in a continuous co-culture of Clostridium ljungdahlii and Clostridium kluyveri with in-line product extraction. Front. Microbiol. 7:1773. doi: $10.3389 /$ fmicb.2016.01773

Richter, H., Molitor, B., Wei, H., Chen, W., Aristilde, L., and Angenent, L. T. (2016b). Ethanol production in syngas-fermenting Clostridium ljungdahlii is controlled by thermodynamics rather than by enzyme expression. Energ. Environ. Sci. 9, 2392-2399. doi: 10.1039/C6EE01108J

Rittmann, S., and Herwig, C. (2012). A comprehensive and quantitative review of dark fermentative biohydrogen production. Microb. Cell Fact. 11:115. doi: 10.1186/1475-2859-11-115

Saeki, K., and Kumagai, H. (1998). The $r n f$ gene products in Rhodobacter capsulatus play an essential role in nitrogen fixation during anaerobic DMSO-dependent growth in the dark. Arch. Microbiol. 169, 464-467. doi: $10.1007 /$ s002030050598

Salcedo-Vite, K., Sigala, J. C., Segura, D., Gosset, G., and Martinez, A. (2019). Acinetobacter baylyi ADP1 growth performance and lipid accumulation on different carbon sources. Appl. Microbiol. Biotechnol. 103, 6217-6229. doi: 10.1007/s00253-019-09910-z

Schaupp, A., and Ljungdahl, L. G. (1974). Purification and properties of acetate kinase from Clostridium thermoaceticum. Arch. Microbiol. 100, 121-129. doi: 10.1007/BF00446312

Schiel-Bengelsdorf, B., and Dürre, P. (2012). Pathway engineering and synthetic biology using acetogens. FEBS Lett. 586, 2191-2198. doi: 10.1016/j.febslet.2012.04.043

Schink, B. (1997). Energetics of syntrophic cooperation in methanogenic degradation. Microbiol. Mol. Biol. Rev. 61, 262-280. doi: $10.1128 / .61 .2 .262-280.1997$

Schink, B., and Friedrich, M. (1994). Energetics of syntrophic fatty acid oxidation. FEMS Microbiol. Rev. 15, 85-94. doi: 10.1111/j.1574-6976.1994.tb00127.x

Schlegel, K., and Müller, V. (2013). Evolution of $\mathrm{Na}^{+}$and $\mathrm{H}^{+}$ bioenergetics in methanogenic archaea. Biochem. Soc. Trans. 41, 421-426. doi: 10.1042/BST20120294

Schmehl, M., Jahn, A., Meyer zu Vilsendorf, A., Hennecke, S., Masepohl, B., Schuppler, M., et al. (1993). Identification of a new class of nitrogen fixation genes in Rhodobacter capsulatus: a putative membrane complex involved in electron transport to nitrogenase. Mol. Gen. Genet. 241, 602-615. doi: 10.1007/BF00279903

Schoelmerich, M. C., Katsyv, A., Dönig, J., Hackmann, T. J., and Müller, V. (2020). Energy conservation involving 2 respiratory circuits. Proc. Natl. Acad. Sci. U.S.A. 117, 1167-1173. doi: 10.1073/pnas.1914939117

Schoelmerich, M. C., Katsyv, A., Sung, W., Mijic, V., Wiechmann, A., Kottenhahn, P., et al. (2018). Regulation of lactate metabolism in the acetogenic bacterium Acetobacterium woodii. Environ. Microbiol. 20, 4587-4595. doi: $10.1111 / 1462-2920.14412$

Schoelmerich, M. C., and Müller, V. (2019). Energy conservation by a hydrogenase-dependent chemiosmotic mechanism in an ancient metabolic pathway. Proc. Natl. Acad. Sci. U.S.A. 116, 6329-6334. doi: 10.1073/pnas. 1818580116

Schoelmerich, M. C., and Müller, V. (2020). Energy-converting hydrogenases: the link between $\mathrm{H}_{2}$ metabolism and energy conservation. Cell. Mol. Life Sci. 77, 1461-1481. doi: 10.1007/s00018-019-03329-5
Schuchmann, K., and Müller, V. (2012). A bacterial electron bifurcating hydrogenase. J. Biol. Chem. 287, 31165-31171. doi: 10.1074/jbc.M112.395038

Schuchmann, K., and Müller, V. (2013). Direct and reversible hydrogenation of $\mathrm{CO}_{2}$ to formate by a bacterial carbon dioxide reductase. Science 342, 1382-1385. doi: $10.1126 /$ science. 1244758

Schuchmann, K., and Müller, V. (2014). Autotrophy at the thermodynamic limit of life: a model for energy conservation in acetogenic bacteria. Nat. Rev. Microbiol. 12, 809-821. doi: 10.1038/nrmicro3365

Schuchmann, K., and Müller, V. (2016). Energetics and application of heterotrophy in acetogenic bacteria. Appl. Environ. Microbiol. 82, 4056-4069. doi: 10.1128/AEM.00882-16

Schut, G. J., and Adams, M. W. (2009). The iron-hydrogenase of Thermotoga maritima utilizes ferredoxin and NADH synergistically: a new perspective on anaerobic hydrogen production. J. Bacteriol. 191, 4451-4457. doi: 10.1128/JB.01582-08

Schwarz, F. M., and Müller, V. (2020). Whole-cell biocatalysis for hydrogen storage and syngas conversion to formate using a thermophilic acetogen. Biotechnol. Biofuels 13:32. doi: 10.1186/s13068-020-1670-x

Schwarz, F. M., Schuchmann, K., and Müller, V. (2018). Hydrogenation of $\mathrm{CO}_{2}$ at ambient pressure catalyzed by a highly active thermostable biocatalyst. Biotechnol. Biofuels 11:237. doi: 10.1186/s13068-018-1236-3

Seifritz, C., Daniel, S. L., Gößner, A., and Drake, H. L. (1993). Nitrate as a preferred electron sink for the acetogen Clostridium thermoaceticum. J. Bacteriol. 175, 8008-8013. doi: 10.1128/JB.175.24.8008-8013.1993

Seifritz, C., Drake, H. L., and Daniel, S. L. (2003). Nitrite as an energy-conserving electron sink for the acetogenic bacterium Moorella thermoacetica. Curr. Microbiol. 46, 329-333. doi: 10.1007/s00284-002-3830-6

Seifritz, C., Fröstl, J. M., Drake, H. L., and Daniel, S. L. (2002). Influence of nitrate on oxalate- and glyoxylate-dependent growth and acetogenesis by Moorella thermoacetica. Arch. Microbiol. 178, 457-464. doi: 10.1007/s00203-002-0475-6

Seitz, H. J., Schink, B., Pfennig, N., and Conrad, R. (1990). Energetics of syntrophic ethanol oxidation in defined chemostat cocultures. Arch. Microbiol. 155, 89-93. doi: 10.1007/BF00291280

Seravalli, J., Kumar, M., Lu, W. P., and Ragsdale, S. W. (1997). Mechanism of carbon monoxide oxidation by the carbon monoxide dehydrogenase/acetylCoA synthase from Clostridium thermoaceticum: kinetic characterization of the intermediates. Biochemistry 36, 11241-11251. doi: 10.1021/bi970590m

Stams, A. J. M. (1994). Metabolic interactions between anaerobic bacteria in methanogenic environments. Antonie van Leeuwenhoek 66, 271-294. doi: $10.1007 /$ BF00871644

Stams, A. J. M., and Plugge, C. M. (2009). Electron transfer in syntrophic communities of anaerobic bacteria and archaea. Nat. Rev. Microbiol. 7, 568-577. doi: $10.1038 /$ nrmicro2166

Syu, M. J. (2001). Biological production of 2,3-butanediol. Appl. Microbiol. Biotechnol. 55, 10-18. doi: 10.1007/s002530000486

Thauer, R. K., Jungermann, K., and Decker, K. (1977). Energy conservation in chemotrophic anaerobic bacteria. Bact. Rev. 41, 100-180. doi: 10.1128/MMBR.41.1.100-180.1977

Thöny-Meyer, L. (1997). Biogenesis of respiratory cytochromes in bacteria. Microbiol. Mol. Biol. Rev. 61, 337-376. doi: 10.1128/.61.3.337-376.1997

Tremblay, P. L., Zhang, T., Dar, S. A., Leang, C., and Lovley, D. R. (2012). The Rnf complex of Clostridium ljungdahlii is a proton-translocating ferredoxin:NAD ${ }^{+}$ oxidoreductase essential for autotrophic growth. Mbio 4, e00406-00412. doi: $10.1128 / \mathrm{mBio} .00406-12$

Tschech, A., and Pfennig, N. (1984). Growth yield increase linked to caffeate reduction in Acetobacterium woodii. Arch. Microbiol. 137, 163-167. doi: $10.1007 /$ BF00414460

Turner, N. J. (2003). Directed evolution of enzymes for applied biocatalysis. Trends Biotechnol. 21, 474-478. doi: 10.1016/j.tibtech.2003.09.001

van Leeuwen, B. N., van der Wulp, A. M., Duijnstee, I., van Maris, A. J., and Straathof, A. J. (2012). Fermentative production of isobutene. Appl. Microbiol. Biotechnol. 93, 1377-1387. doi: 10.1007/s00253-0113853-7

Visser, M., Pieterse, M. M., Pinkse, M. W., Nijsse, B., Verhaert, P. D., de Vos, W. M., et al. (2016). Unravelling the one-carbon metabolism of the acetogen Sporomusa strain An4 by genome and proteome analysis. Environ. Microbiol. 18, 2843-2855. doi: 10.1111/1462-2920. 12973 
Wallimann, T., Wyss, M., Brdiczka, D., Nicolay, K., and Eppenberger, H. M. (1992). Intracellular compartmentation, structure and function of creatine kinase isoenzymes in tissues with high and fluctuating energy demands: the 'phosphocreatine circuit' for cellular energy homeostasis. Biochem. J. 281, 21-40. doi: 10.1042/bj2810021

Wang, S., Huang, H., Kahnt, J., Müller, A. P., Köpke, M., and Thauer, R. K. (2013a). NADP-specific electron-bifurcating [FeFe]-hydrogenase in a functional complex with formate dehydrogenase in Clostridium autoethanogenum grown on CO. J. Bacteriol. 195, 4373-4386. doi: 10.1128/JB.00678-13

Wang, S., Huang, H., Kahnt, J., and Thauer, R. K. (2013b). Clostridium acidurici electron-bifurcating formate dehydrogenase. App. Environ. Microbiol. 79, 6176-6179. doi: 10.1128/AEM.02015-13

Wang, S., Huang, H., Moll, J., and Thauer, R. K. (2010). NADP ${ }^{+}$reduction with reduced ferredoxin and $\mathrm{NADP}^{+}$reduction with $\mathrm{NADH}$ are coupled via an electron bifurcating enzyme complex in Clostridium kluyveri. J. Bacteriol. 192, 5115-5123. doi: 10.1128/JB.00612-10

Weghoff, M. C., Bertsch, J., and Müller, V. (2015). A novel mode of lactate metabolism in strictly anaerobic bacteria. Environ. Microbiol. 17, 670-677. doi: $10.1111 / 1462-2920.12493$

Welte, C., and Deppenmeier, U. (2014). Bioenergetics and anaerobic respiratory chains of aceticlastic methanogens. Biochim. Biophys. Acta 1837, 1130-1147. doi: 10.1016/j.bbabio.2013.12.002

Welte, C., Krätzer, C., and Deppenmeier, U. (2010). Involvement of Ech hydrogenase in energy conservation of Methanosarcina mazei. FEBS J. 277, 3396-3403. doi: 10.1111/j.1742-4658.2010.07744.x

Westphal, L., Wiechmann, A., Baker, J., Minton, N. P., and Müller, V. (2018). The Rnf complex is an energy coupled transhydrogenase essential to reversibly link cellular NADH and ferredoxin pools in the acetogen Acetobacterium woodii. J. Bacteriol. 200, e00357-e00318. doi: 10.1128/JB.00357-18

White, H., Strobl, G., Feicht, R., and Simon, H. (1989). Carboxylic acid reductase: a new tungsten enzyme catalyses the reduction of nonactivated carboxylic acids to aldehydes. Eur. J. Biochem. 184, 89-96. doi: 10.1111/j.1432-1033.1989.tb14993.x

Wiechmann, A., Ciurus, S., Oswald, F., Seiler, V. N., and Müller, V. (2020). It does not always take two to tango: "Syntrophy" via hydrogen cycling in one bacterial cell. ISME J. 14, 1561-1570 doi: 10.1038/s41396-020-0627-1
Winter, J. U., and Wolfe, R. S. (1980). Methane formation from fructose by syntrophic associations of Acetobacterium woodii and different strains of methanogens. Arch. Microbiol. 124, 73-79. doi: 10.1007/BF00407031

Wohlfarth, G., and Diekert, G. (1991). Thermodynamics of methylenetetrahydrofolate reduction to methyltetrahydrofolate and its implications for the energy metabolism of homoacetogenic bacteria. Arch. Microbiol. 155, 378-381. doi: 10.1007/BF00243458

Wolfe, R. S. (1971). Microbial formation of methane. Adv. Microbiol. Physiol. 6, 107-146. doi: 10.1016/S0065-2911(08)60068-5

Wood, H. G., Ragsdale, S. W., and Pezacka, E. (1986). The acetyl-CoA pathway of autotrophic growth. FEMS Microbiol. Rev. 39, 345-362. doi: $10.1111 /$ j.1574-6968.1986.tb01865.x

Yakushi, T., and Matsushita, K. (2010). Alcohol dehydrogenase of acetic acid bacteria: structure, mode of action, and applications in biotechnology. Appl. Microbiol. Biotechnol. 86, 1257-1265. doi: 10.1007/s00253-010-2529-z

Yamamoto, I., Saiki, T., Liu, S. M., and Ljungdahl, L. G. (1983). Purification and properties of NADP-dependent formate dehydrogenase from Clostridium thermoaceticum, a tungsten-selenium-iron protein. J. Biol. Chem. 258, $1826-1832$.

Zehnder, A. J., and Brock, T. D. (1979). Methane formation and methane oxidation by methanogenic bacteria. J. Bacteriol. 137, 420-432. doi: 10.1128/JB.137.1.420-432.1979

Zellner, G., and Winter, J. (1987). Secondary alcohols as hydrogen donors for $\mathrm{CO}_{2}$-reduction by methanogens. FEMS Microbiol. Lett. 44, 323-328. doi: 10.1111/j.1574-6968.1987.tb02309.x

Conflict of Interest: The authors declare that the research was conducted in the absence of any commercial or financial relationships that could be construed as a potential conflict of interest.

Copyright $\odot 2020$ Katsyv and Müller. This is an open-access article distributed under the terms of the Creative Commons Attribution License (CC BY). The use, distribution or reproduction in other forums is permitted, provided the original author(s) and the copyright owner(s) are credited and that the original publication in this journal is cited, in accordance with accepted academic practice. No use, distribution or reproduction is permitted which does not comply with these terms. 